\title{
LY6E impairs coronavirus fusion and confers immune control of viral disease
}

\author{
Stephanie Pfaender ${ }^{1,2,3,16}$, Katrina B. Mar ${ }^{4,16}$, Eleftherios Michailidis $\mathbb{D}^{5}$, Annika Kratzel ${ }^{1,2,6}$, \\ Ian N. Boys ${ }^{4}$, Philip V'kovski ${ }^{1,2}$, Wenchun Fan ${ }^{4}{ }^{4}$, Jenna N. Kelly ${ }^{1,2}$, Dagny Hirt ${ }^{1,2}$, \\ Nadine Ebert ${ }^{1,2}$, Hanspeter Stalder (1) 1,2, Hannah Kleine-Weber,8, Markus Hoffmann (1) ${ }^{7}$, \\ Hans-Heinrich Hoffmann ${ }^{5}{ }^{5}$, Mohsan Saeed ${ }^{5,9,10}$, Ronald Dijkman ${ }^{10,2,11,12}$, Eike Steinmann ${ }^{3}$, \\ Mary Wight-Carter ${ }^{13}$, Matthew B. McDougal (1) ${ }^{4}$, Natasha W. Hanners ${ }^{14}{ }^{14}$, Stefan Pöhlmann ${ }^{7,8}$,

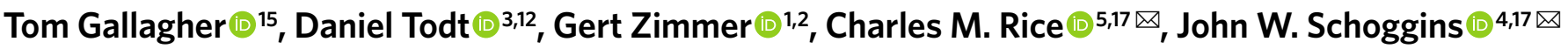 \\ and Volker Thiel 1 1,2,17凶
}

\begin{abstract}
Zoonotic coronaviruses (CoVs) are substantial threats to global health, as exemplified by the emergence of two severe acute respiratory syndrome CoVs (SARS-CoV and SARS-CoV-2) and Middle East respiratory syndrome CoV (MERS-CoV) within two decades ${ }^{1-3}$. Host immune responses to CoVs are complex and regulated in part through antiviral interferons. However, interferon-stimulated gene products that inhibit CoVs are not well characterized ${ }^{4}$. Here, we show that lymphocyte antigen 6 complex, locus E (LY6E) potently restricts infection by multiple CoVs, including SARS-CoV, SARS-CoV-2 and MERS-CoV. Mechanistic studies revealed that LY6E inhibits CoV entry into cells by interfering with spike protein-mediated membrane fusion. Importantly, mice lacking Ly6e in immune cells were highly susceptible to a murine CoV-mouse hepatitis virus. Exacerbated viral pathogenesis in Ly6e knockout mice was accompanied by loss of hepatic immune cells, higher splenic viral burden and reduction in global antiviral gene pathways. Accordingly, we found that constitutive Ly6e directly protects primary B cells from murine CoV infection. Our results show that LY6E is a critical antiviral immune effector that controls $\mathrm{CoV}$ infection and pathogenesis. These findings advance our understanding of immune-mediated control of $\mathrm{CoV}$ in vitro and in vivo-knowledge that could help inform strategies to combat infection by emerging CoVs.
\end{abstract}

Coronaviruses (CoVs) are enveloped RNA viruses with broad host tropism and documented capability to cross the species barrier to infect humans $s^{5}$. The mammalian innate immune response controls $\mathrm{CoV}$ infection partly through the action of interferons (IFNs) ${ }^{4,6,7}$. IFNs inhibit viral infection by inducing hundreds of genes, many of which encode antiviral effectors ${ }^{8}$. The IFN-stimulated genes (ISGs) that inhibit $\mathrm{CoV}$ infection are not well defined $^{4}$. To address this knowledge gap, we screened our published library of $>350$ human ISG complementary DNAs ${ }^{9,10}$ in human hepatoma cells for antiviral activity against the endemic human CoV 229E (HCoV-229E) (Supplementary Tables 1 and 2). The ISG lymphocyte antigen 6 complex, locus E (LY6E) strikingly inhibited HCoV-229E infection (Fig. 1a,b and Extended Data Fig. 1a). This was unexpected since we and others previously reported that LY6E enhances cellular infection by influenza A virus, flaviviruses and human immunodeficiency virus 1 (HIV-1) (refs. ${ }^{11-13}$ ), with HIV-1 being an exception, with opposing roles of LY6E described ${ }^{14}$. To verify this result, we generated stable cell lines ectopically expressing LY6E and infected cells with diverse CoVs. In addition to HCoV229E (Fig. 1c), LY6E significantly reduced infection by HCoV-OC43 (Fig. 1d), Middle East respiratory syndrome CoV (MERS-CoV; Fig. 1e), severe acute respiratory syndrome CoV (SARS-CoV; Fig. 1f) and the recently emerged SARS-CoV-2 (Fig. $1 \mathrm{~g}$ and Extended Data Fig. 1b). The antiviral effect of LY6E extended beyond human CoVs and decreased infection by the murine $\mathrm{CoV}$ mouse hepatitis virus (MHV) (Fig. 1h). Given the zoonotic origin of MERS-CoV, SARS-CoV and SARS-CoV-2, all of which are suspected to have originated from bats, we next tested the antiviral potential of select LY6E orthologues. All LY6E orthologues inhibited HCoV-229E (Extended Data Fig. 1c). Recent surveillance of Kenyan camels - the main viral reservoir for MERS-CoV-indicates active circulation of the zoonotic $\mathrm{CoV}^{13}$. Human and camel LY6E restricted MERS-CoV infection (Extended Data Fig. 1d). To confirm the presence of LY6E in respiratory cells that are targeted by human CoVs, we examined expression in primary human airway epithelial cells (hAECs) by single-cell RNA sequencing (scRNA-seq). LY6E was widely expressed in all cell types, with the greatest levels observed in goblet cells (Fig. 1i). We additionally

IInstitute of Virology and Immunology, Bern, Switzerland. 2Department of Infectious Diseases and Pathobiology, Vetsuisse Faculty, University of Bern, Bern, Switzerland. ${ }^{3}$ Department for Molecular and Medical Virology, Ruhr-Universität Bochum, Bochum, Germany. ${ }^{4}$ Department of Microbiology, University of Texas Southwestern Medical Center, Dallas, TX, USA. ${ }^{5}$ Laboratory of Virology and Infectious Disease, The Rockefeller University, New York, NY, USA. ${ }^{6}$ Graduate School for Cellular and Biomedical Sciences, University of Bern, Bern, Switzerland. ${ }^{7}$ Deutsches Primatenzentrum, Leibniz-Institut für Primatenforschung, Göttingen, Germany. ${ }^{8}$ Faculty of Biology and Psychology, Universität Göttingen, Göttingen, Germany. ${ }^{9}$ Department of Biochemistry, Boston University School of Medicine, Boston, MA, USA. ${ }^{10}$ National Emerging Infectious Diseases Laboratories, Boston University, Boston, MA, USA. ${ }^{11}$ Institute for Infectious Diseases, University of Bern, Bern, Switzerland. ${ }^{12}$ European Virus Bioinformatics Center (EVBC), Jena, Germany. ${ }^{13}$ Animal Resource Center, University of Texas Southwestern Medical Center, Dallas, TX, USA. ${ }^{14}$ Department of Pediatrics, University of Texas Southwestern Medical Center, Dallas, TX, USA. ${ }^{15}$ Department of Microbiology and Immunology, Loyola University Chicago, Chicago, IL, USA. ${ }^{16}$ These authors contributed equally: Stephanie Pfaender, Katrina B. Mar. ${ }^{17}$ These authors jointly supervised this work: Charles M. Rice, John W. Schoggins, Volker Thiel.

凶e-mail: ricec@rockefeller.edu; john.schoggins@utsouthwestern.edu; volker.thiel@vetsuisse.unibe.ch 
assessed the expression of known human CoV receptors in hAECs by scRNA-seq and observed broad expression of the HCoV-229E receptor CD13, the MERS-CoV receptor DPP4 and the SARS-CoV and SARS-CoV-2 receptor ACE2 in multiple cell types (Extended Data Fig. 1e-g). Infection of hAECs with SARS-CoV-2, but not SARS-CoV, potently induced the expression of LY6E in hAECs at $3 \mathrm{~d}$ post-infection (Fig. 1j). LY6E has previously been shown to restrict HIV-1 infection by promoting internalization of the receptor CD4 (ref. $\left.{ }^{14}\right)$. When we ectopically expressed angiotensin-converting enzyme 2 (ACE2) in human hepatoma cells, SARS-CoV-2 infectivity increased, but LY6E still restricted SARS-CoV-2 (Fig. 1k,1 and Extended Data Fig. 1h). Importantly, total levels of ectopically expressed ACE2 were unaltered by LY6E expression (Extended Data Fig. 1i). Furthermore, LY6E expression had no effect on cell surface levels of other CoV receptors (that is, CD13 (Extended Data Fig. 1j) and DPP4 (Extended Data Fig. 1k)). Collectively, our data show that LY6E is a constitutively expressed ISG product that restricts infection by endemic and pandemic CoVs without modulating the expression of viral receptors.

To test the role of endogenous LY6E in controlling CoV infections, we used CRISPR-Cas9 gene editing to ablate LY6E expression in human lung adenocarcinoma cells (Fig. $1 \mathrm{~m}$ ). This cell line was selected as human hepatoma cells do not express LY6E irrespective of IFN treatment ${ }^{11}$. LY6E knockout cells were more susceptible to HCoV229E (Fig. 1n). Reconstitution with a CRISPR-resistant LY6E variant restored antiviral activity in knockout cells (Fig. 1o,p). Strikingly, the LY6E-mediated restriction in hepatoma cells was largely specific to CoVs. Among ten genetically divergent viruses tested, only hepatitis $\mathrm{C}$ virus was also restricted (Extended Data Fig. 11).

LY6E is a member of the LY6/uPAR family of glycosylphosphatidylinositol-anchored proteins, and is implicated in diverse cellular processes ${ }^{15}$. To evaluate the specificity of LY6E for inhibiting CoVs, we ectopically expressed selected LY6/uPAR proteins ${ }^{11}$ and infected Huh7 cells with HCoV-229E. Only LY6E inhibited CoV infection (Extended Data Fig. $1 \mathrm{~m}$ ). We previously showed that a conserved residue (L36) is required for LY6E-mediated enhancement of influenza A virus ${ }^{11}$. L36 was also required to restrict $\mathrm{HCoV}-229 \mathrm{E}$ infection (Extended Data Fig. 1n). These data suggest a conserved functional domain that is responsible for both the virus-enhancing and virus-restricting phenotypes.

Next, we investigated the effect of LY6E on specific steps of the virus replication cycle. First, we tested whether LY6E restricts CoV attachment to the cell surface, and observed no effect on $\mathrm{HCoV}$ 229E binding (Extended Data Fig. 2a). To test whether LY6E restricts viral entry, we used a vesicular stomatitis virus (VSV) pseudoparticle system bearing CoV spike proteins. Strikingly,
LY6E significantly inhibited VSV pseudoparticle entry mediated by spike proteins from HCoV-229E (Fig. 2a), MERS-CoV (Fig. 2a), SARS-CoV (Fig. 2b) and SARS-CoV-2 (Fig. 2b). Entry mediated by VSV glycoprotein G (VSV-G) was not affected by LY6E (Fig. 2a,b). Time-course experiments revealed that LY6E had no effect on $\mathrm{CoV}$ translation, replication, assembly or release, as assessed with HCoV-229E (Extended Data Fig. 2b-f). To further narrow down the entry phenotype, we tested whether LY6E interferes with the fusion of viral and cellular membranes. To this end, we performed a syncytia formation assay using propagation-competent VSV pseudoviruses co-expressing $\mathrm{CoV}$ spike protein and a green fluorescent protein (GFP) reporter $\left(\mathrm{VSV}^{\star} \Delta \mathrm{G}(\mathrm{CoV} S)\right.$ ) (Extended Data Fig. 3a). LY6E potently inhibited $\mathrm{CoV}$ spike protein-mediated syncytia formation (Fig. 2c,d). To determine whether LY6E impairs spike protein expression or maturation, we also performed a heterologous syncytia formation assay. CoV-resistant hamster cells infected with the trans-complemented GFP reporter $\mathrm{VSV}^{\star} \Delta \mathrm{G}(\mathrm{CoV})$ were co-cultured with susceptible target cells that ectopically expressed LY6E. LY6E again significantly blocked syncytia formation, demonstrating that LY6E inhibits spike protein-mediated fusion and not spike protein expression or maturation (Extended Data Fig. 3b,c). As membrane fusion can occur without syncytia formation, we also performed a quantitative fusion assay in which the mixing of cell contents results in complementation of split-luciferase/split-GFP (Fig. 2e-h). Cells co-transfected with plasmids encoding $\mathrm{CoV}$ spike proteins and split-GFP were mixed with susceptible target cells co-expressing LY6E or vector control and the complementary fragment of split-GFP. LY6E reduced CoV S-mediated cell-cell fusion of HCoV-229E (Fig. 2e,f), MERS-CoV (Fig. 2e,f) and SARS-CoV-2 (Fig. $2 \mathrm{~g}, \mathrm{~h}$ ), as visualized by a reduction of GFP-positive syncytia, indicating that LY6E blocks the fusion of viral and cellular membranes. Importantly, no effect on control cells (mCherry-transfected or VSV-G) could be observed (Fig. 2e-h). SARS-CoV did not induce cell-cell fusion in this experimental setup, consistent with recent observations (Fig. 2g,h) ${ }^{16,17}$. Collectively, our results demonstrate that LY6E specifically inhibits $\mathrm{CoV}$ spike protein-mediated membrane fusion, which is required for productive viral entry.

Next, we addressed whether LY6E influences proteolytic activation of the spike protein. After spike protein-mediated binding to the respective receptor, host proteases cleave the spike protein, activating membrane fusion ${ }^{18}$ at cell surfaces or within endosomes ${ }^{19}$. Inhibitors of cell surface and endosomal proteases suppressed infection but had no effect on LY6E-mediated restriction of $\mathrm{CoV}$ infection (Extended Data Fig. 4a-c). Proteolytic activation is also suppressed by cleavage site mutations ${ }^{19,20}$. Mutation of S1/S2 and S2'

Fig. 1 | ISG screen identifies LY6E as a potent CoV restriction factor. a, Duplicate screens depicting HCoV-229E infection (24h post-infection) in Huh7 cells ectopically expressing ISGs. b, HCoV-229E infection of Huh7 cells expressing LY6E or control vector (empty) (blue: DAPl; green: HCoV-229E N protein; red: TagRFP encoded in SCRPSY vector). c-h, Effect of stable LY6E expression on diverse CoVs. Cells were infected with HCoV-229E (c), HCoV-OC43 (d), MERS-CoV (e), SARS-CoV (f), SARS-CoV-2 (g) or MHV-Gluc (h). RLU, relative light units. i, Uniform manifold approximation and projection (UMAP) visualization of $L Y 6 E$ expression and distribution in primary hAEC cultures from two donors by scRNA-seq. $\mathbf{j}$, Induction of $\angle Y 6 E$ in mock or infected hAECs from three donors by RNA-seq. k, SARS-CoV-2 infection of LY6E or control vector (FLuc) Huh7.5 cells co-expressing human ACE2 (blue: DAPI; green: SARS-CoV-2 dsRNA; red: TagRFP encoded in SCRPSY-ACE2 vector). I, Quantification of the dsRNA mean fluorescence intensity (MFI) normalized by the number of nuclei in the image. $\mathbf{m}$, Western blot of wild-type (WT) A549 or two LY6E knockout (KO) clones (numbers 3 and 4). $\mathbf{n}$, HCoV-229E infection of wild-type or LY6E knockout A549. o, Western blot of wild-type or LY6E knockout A549 reconstituted with CRISPR-resistant LY6E (CR LY6E) or control vector (empty). p, HCoV-229E infection of CRISPR-resistant LY6E-reconstituted wild-type or LY6E knockout A549. Data represent the means of independent biological replicates $(n=3(\mathbf{c}, \mathbf{d}, \mathbf{f}-\mathbf{h}, \mathbf{j}$ and $\mathbf{I})$ and $n=4(\mathbf{e}, \mathbf{n}$ and $\mathbf{p}))$. Immunofluorescence images are depicted exemplarily from $n=2(\mathbf{b})$ and $n=3$ images (k). In I, seven images per condition were acquired and processed. Scale bars: $200 \mu M(\mathbf{b})$ and $100 \mu M(\mathbf{k})$. Statistical significance was determined by two-tailed unpaired Student's t-test with Welch's correction (c, $\mathbf{d}, \mathbf{f}$ and $\mathbf{h}$ ), one-tailed Mann-Whitney $U$-test (e), two-tailed ratio-paired Student's t-test (g), one-way analysis of variance (ANOVA) followed by Tukey's multiple comparisons test (I) or two-way ANOVA followed by Šidák's or Dunnett's multiple comparisons test ( $\mathbf{n}$ and $\mathbf{p}$ ). For the box plots, centre lines indicate mean values, and upper and lower bounds, respectively, indicate maximum and minimum replicate values (j and $\mathbf{I})$. Error bars represent s.d. $P$ values: ${ }^{\star \star} P=0.0088(\mathbf{c}) ;{ }^{\star \star \star} P=0.0001(\mathbf{d}) ;{ }^{\star} P=0.0143$ (e); ${ }^{\star} P=0.0286(\mathbf{f}) ;{ }^{\star} P=0.0101(\mathbf{g}) ;{ }^{\star \star \star} P=0.0010(\mathbf{h}) ;{ }^{\star \star} P=0.0035,{ }^{\star \star} P=0.0091$ and ${ }^{\star \star} P=0.0057$ (left to right in $\mathbf{l}$ ); ${ }^{\star \star} P=0.0073$ and ${ }^{\star \star} P=0.0033$ (left to right in $\mathbf{n}$ ); and ${ }^{\star \star} P=0.0013$ and ${ }^{\star \star \star} P=0.0001$ (left to right in $\mathbf{p}$ ). NS, not significant. 
in the spike protein of MERS-CoV reduced activation (Extended Data Fig. 4d $)^{19,20}$. LY6E overexpression did not affect S1/S2 cleavage (Extended Data Fig. 4e,f) and did not affect the level of mutant
MERS-CoV S pseudoparticle cell entry (Extended Data Fig. 4g). Collectively, our data indicate that restriction of viral fusion is independent of spike protein activation.

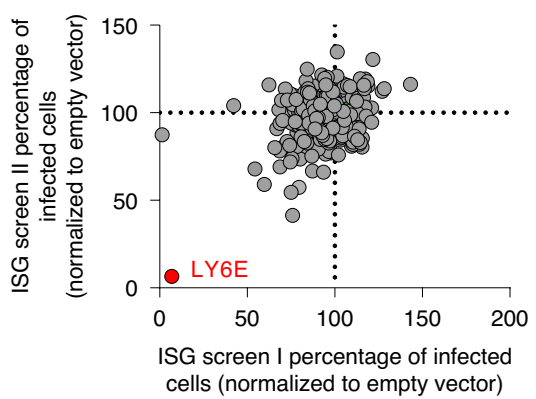

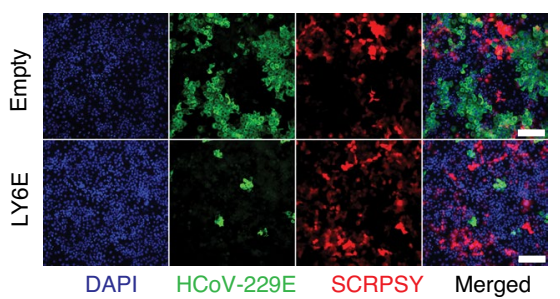
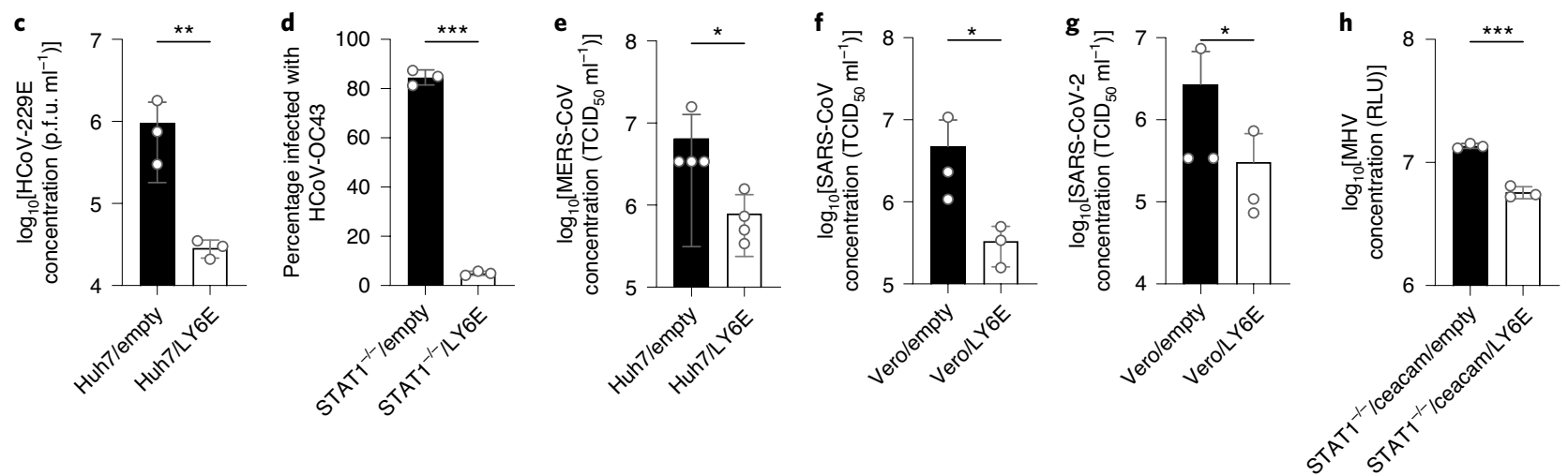

j

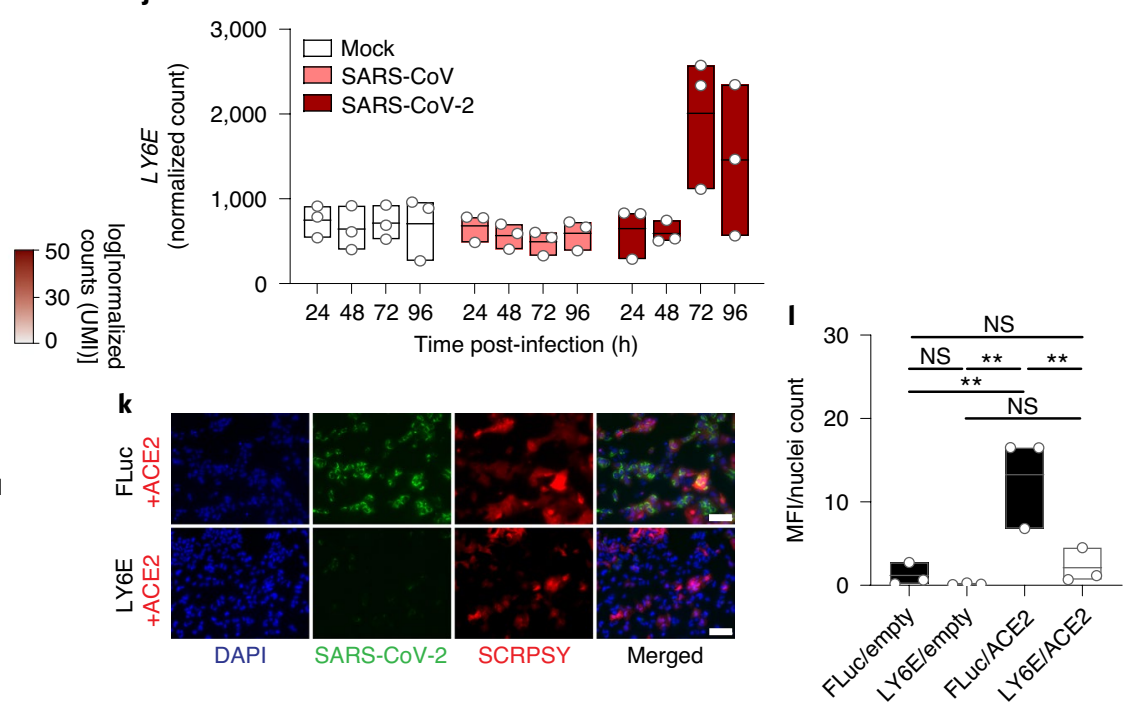

m

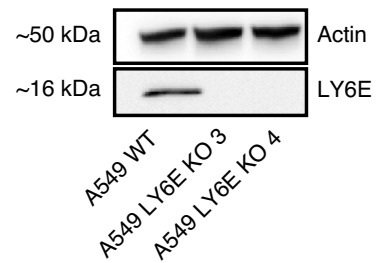

n



o

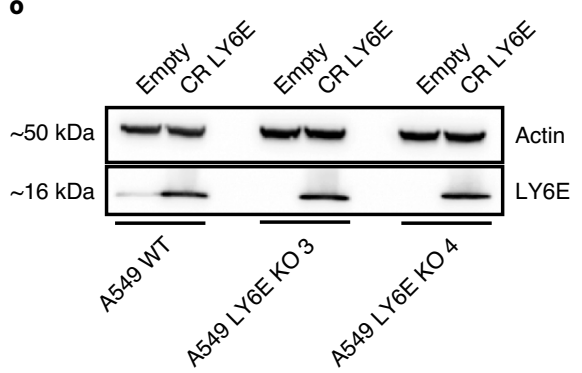

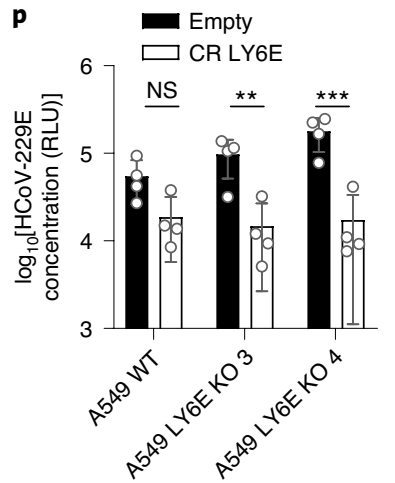



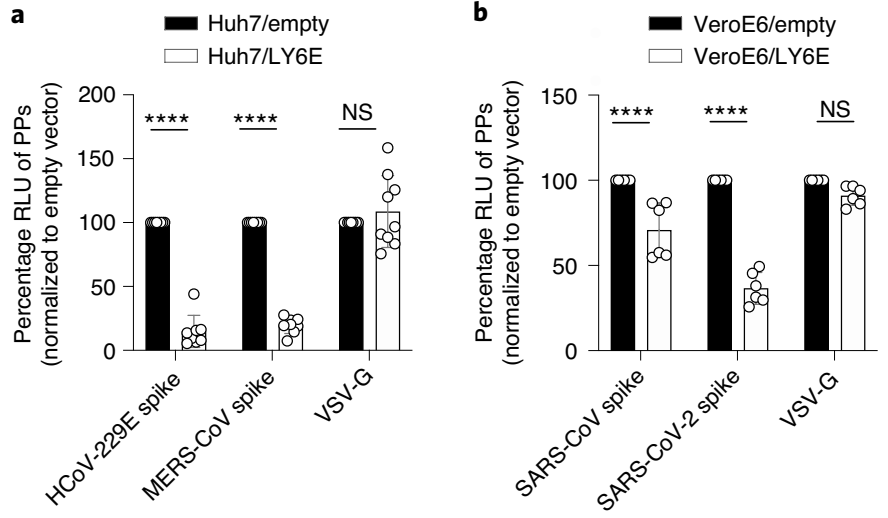

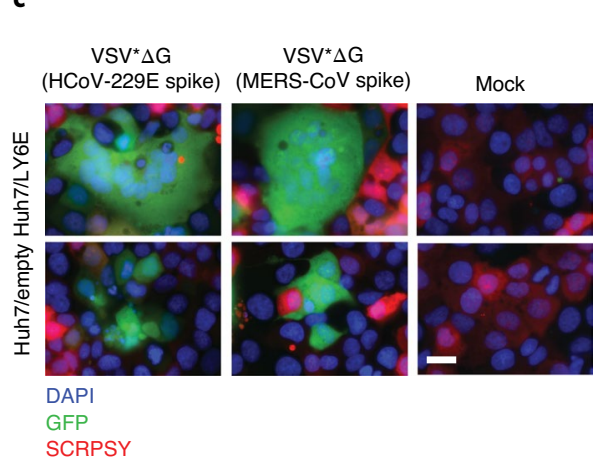

d

- Huh7/empty $\square$ Huh7/LY6E
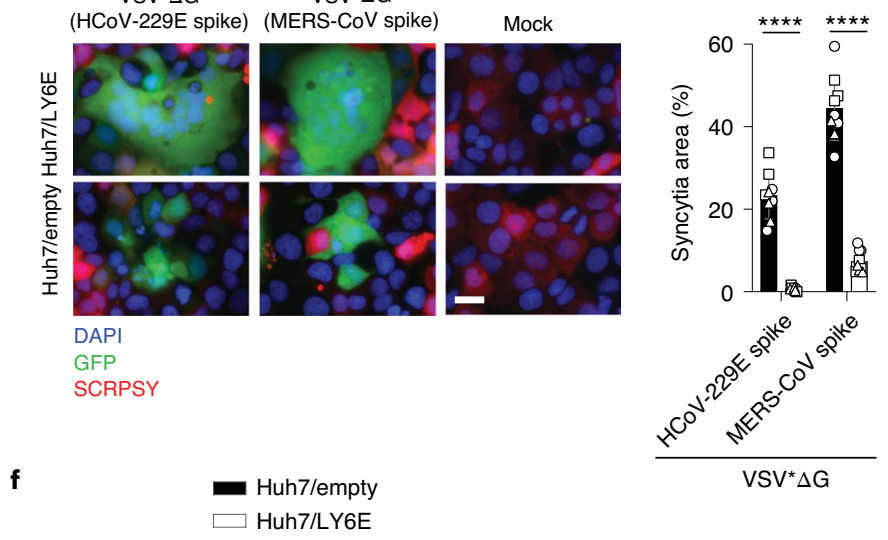

$\mathrm{VSV}^{*} \Delta \mathrm{G}$

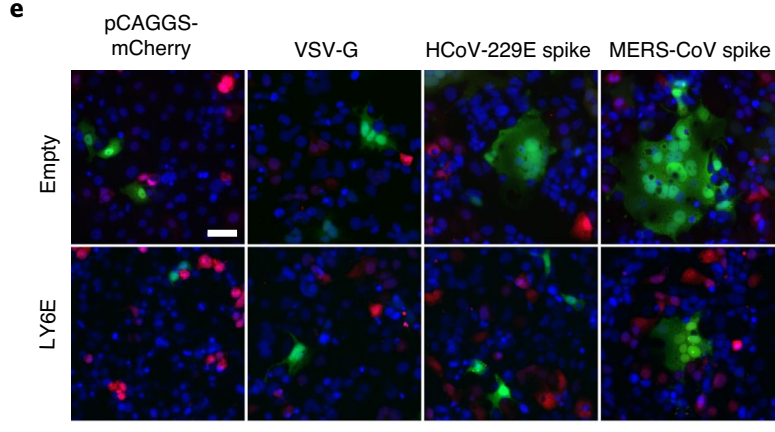

Huh7

g

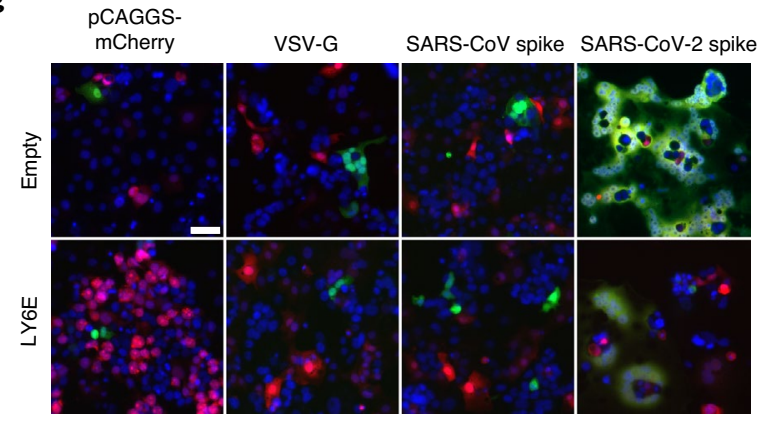

VeroE6

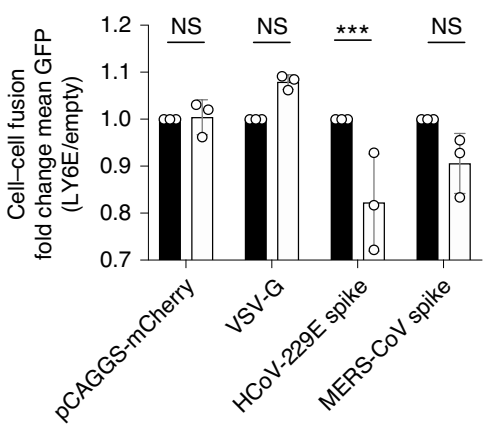

h

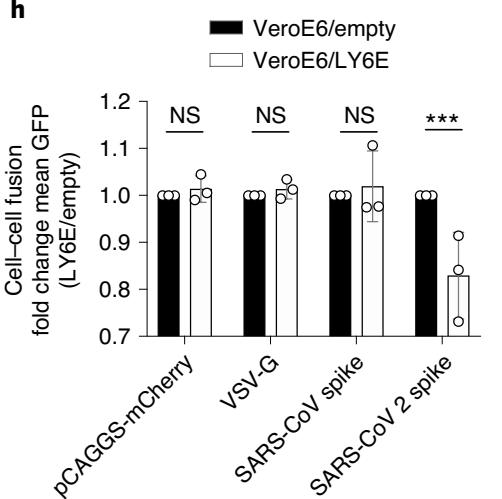

Fig. 2 | LY6E inhibits viral membrane fusion and syncytia formation. a,b, VSV pseudoparticles (PPs) harbouring spike proteins from HCoV-229E, MERS-CoV and G protein from VSV (a) or SARS-CoV, SARS-CoV-2 and G protein from VSV (b) were inoculated on LY6E- or empty vector-expressing cells. The virus entry efficiency was quantified by measuring the virus-encoded luciferase reporter activity. c, VSV pseudoparticles expressing VSV-G protein on their surface and encoding CoV spike protein and GFP $\left(V_{S V}{ }^{\star} \Delta G(C o V S)\right.$ ) were inoculated with LY6E- or empty vector-expressing Huh7. Syncytia formation was analysed by immunofluorescence microscopy (blue: DAPI; green: GFP; red: TagRFP inserted in SCRPSY vector). d, Quantification of $V_{S V}{ }^{\star} \Delta G(C o V S)$-induced syncytia, depicted as the percentage syncytia area. Three independent areas were analysed per biological replicate (circles, squares and triangles, respectively). e-h, Cell-cell fusion was analysed by co-incubating cells transfected with plasmids encoding mCherry, VSV-G protein or CoV spike proteins and a split-luciferase/split-GFP construct together with CoV-permissive LY6E-expressing or control cells transfected with the complementary fragment of split-luciferase/split-GFP. GFP complementation was analysed via immunofluorescence microscopy of GFP-positive syncytia. In $\mathbf{e}$ and $\mathbf{g}$, an exemplary image of GFP-positive syncytia is depicted. $\mathbf{f}, \mathbf{h}$, Quantification of GFP-positive syncytia. Four images per condition were acquired and processed. Data were normalized to empty controls and are depicted as fold changes in mean GFP expression. Data represent the means of independent biological replicates ( $n=8$ for HCoV-229E S and MERS-CoV-S, $n=9$ for VSV-G) (a); $n=6(\mathbf{b}) ; n=3$ (d); and $n=3$ (f and $\mathbf{h})$ ). Statistical significance was determined by two-way ANOVA followed by Šidák's multiple comparisons test (a-d, f and $\mathbf{h}$ ). Scale bars: $20 \mu \mathrm{M}$ (c) and $50 \mu \mathrm{M}$ (e and $\mathbf{g}$ ). Error bars represent s.d. (a, b, d, f and $\mathbf{h}$ ). $P$ values: ${ }^{\star \star \star \star} P=3.3 \times 10^{-16}$ and ${ }^{\star \star \star \star} P=3.6 \times 10^{-15}$ (left to right in $\mathbf{a}$ ); ${ }^{\star \star \star \star} P=1.363 \times 10^{-6}$ and ${ }^{\star \star \star \star} P=4.200 \times 10^{-14}$ (left to right in $\mathbf{b}$ ); ${ }^{\star \star \star \star} P=6.0 \times 10^{-9}$ and ${ }^{\star \star \star \star} P<1.1 \times 10^{-15}$ (left to right in $\mathbf{d}$ ); ${ }^{\star \star \star} P=0.0008$ (f); and ${ }^{\star \star \star} P=0.0008$ (h).

Next, we aimed to evaluate LY6E-mediated CoV restriction in vivo. Systemic genetic ablation of Ly6e in mice is embryonic letha ${ }^{21}$. Therefore, we generated transgenic $L y 6 e^{\mathrm{a} / \mathrm{fl}}$ mice, which are functionally wild type for Ly6e expression, and crossed them with Vav1-iCre mice to ablate Ly6e in immune cells that originate from a haematopoietic stem cell (HSC) progenitor (Extended Data Fig. 5a,b). This genetic model was chosen since immune cells are critical for protection from $\mathrm{CoVs}$ in vivo ${ }^{7,22-26}$. Bone marrow-derived 
macrophages (BMDMs) from $L y 6 e^{\Delta \mathrm{HSC}}$ mice had reduced $L y 6 e$ messenger RNA levels (Extended Data Fig. 5c). The natural mouse pathogen MHV is a well-studied CoV model that causes hepatitis and encephalomyelitis in mice ${ }^{27}$. Ly6 $e^{\Delta \mathrm{HSC}} \mathrm{BMDMs}$ were more susceptible to MHV infection than Ly6 $e^{\mathrm{f} / \mathrm{fl}} \mathrm{BMDMs}$, demonstrating that murine Ly6e is a restriction factor for murine $\mathrm{CoV}$ (Extended Data Fig. 5d).

To determine whether Ly6e is important for controlling CoV infection in vivo, $L y 6 e^{\mathrm{f} / \mathrm{fl}}$ and $L y 6 e^{\Delta \mathrm{HSC}}$ mice were infected with a high dose $\left(5 \times 10^{4}\right.$ plaque-forming units (p.f.u.) $)$ of $\mathrm{MHV}$ that causes sub-lethal hepatitis in wild-type C57BL/6J mice ${ }^{28}$. Since MHV pathogenesis is influenced by sex, with higher levels of viral replication and hepatic damage observed in male mice ${ }^{29}$, we performed independent experiments in male and female mice. $L y 6 e^{\Delta \mathrm{HSC}}$ mice of both sexes rapidly succumbed to MHV infection by day 6 (Fig. 3a,b and Extended Data Fig. 6a,b). To examine viral pathogenesis and immunopathology in infected mice, $L y 6 e^{\mathrm{f} / / \mathrm{fl}}$ and $L y 6 e^{\Delta \mathrm{HSC}}$ mice were infected with the same high dose of MHV and euthanized 3 or $5 \mathrm{~d}$ post-infection. At both time points, female $L y 6 e^{\Delta \mathrm{HSC}}$ mice exhibited significantly higher levels of liver damage, as measured by serum alanine aminotransferase (ALT), while no difference was observed in male mice (Fig. 3c,i and Extended Data Fig. 6c,i). However, hepatic viral burden did not differ in either sex (Fig. 3d,j and Extended Data Fig. 6d,j), possibly due to tissue saturation at this high dose. At a lower dose of MHV (5 p.f.u.), viral burden and liver damage were elevated in female mice, but not in male mice, which exhibited saturated hepatic infection, probably due to increased susceptibility, as previously reported (Extended Data Fig. $7 \mathrm{a}, \mathrm{b}, \mathrm{f}, \mathrm{g})^{29}$. Spleen viral burden was elevated in female and male $L y 6 e^{\Delta \mathrm{HSC}}$ mice at both time points and both doses of MHV (Fig. 3e,k and Extended Data Figs. $6 \mathrm{e}, \mathrm{k}$ and $7 \mathrm{c}, \mathrm{h})$. At $3 \mathrm{~d}$ post-infection, there was no difference in liver necrosis, but inflammation was moderately reduced in female but not male $L y 6 e^{\Delta \mathrm{HSC}}$ mice (Fig. $3 \mathrm{f}-\mathrm{h}$ and Extended Data Fig. $6 \mathrm{f}-\mathrm{h}$ ). By $5 \mathrm{~d}$ post-infection and at both low and high doses of MHV, female $L y 6 e^{\Delta \mathrm{HSC}}$ mice had significantly higher levels of liver necrosis and a reduced presence of mononuclear immune cells (Fig. 31-n and Extended Data Fig. 7d,e), whereas no difference was observed in male mice (Extended Data Figs. 6l-n and $7 \mathrm{i}, \mathrm{j})$. Liver damage in $L y 6 e^{\Delta \mathrm{HSC}}$ mice was further corroborated at an intermediate viral dose $\left(5 \times 10^{3}\right.$ p.f.u. $)$, which resulted in visibly apparent brittleness, pallor and necrotic foci (Extended Data Fig. $7 \mathrm{k}-\mathrm{n}$ ). These data show that Ly6e in HSCs is important for controlling murine $\mathrm{CoV}$ infection.

Next, we used a transcriptomic approach to evaluate the effect of $L y 6 e$ ablation on global gene expression in the liver and spleen of female $L y 6 e^{\mathrm{t} / \mathrm{fl}}$ and $L y 6 e^{\Delta \mathrm{HSC}}$ mice injected with phosphate-buffered saline (PBS) or the high dose of MHV at 3 and $5 \mathrm{~d}$ post-infection. In infected tissues, loss of Ly6e in HSCs correlated with differential gene expression in pathways associated with tissue damage, such as liver-specific metabolic genes, angiogenesis, wound healing and immune response to viruses (Fig. $4 \mathrm{a}-\mathrm{c}$ ). We also observed a striking loss of genes associated with the type I IFN response, inflammation, antigen presentation and $\mathrm{B}$ cells in livers and spleens from infected Ly $6 e^{\Delta \mathrm{HSC}}$ mice (Extended Data Figs. 7o,p and 8).
The histopathology (Fig. 3h,n) and transcriptome data (Fig. 4a-c and Extended Data Figs. 7o,p and 8) prompted us to determine how loss of Ly6e affects immune cell numbers during infection. Absolute numbers of different immune cell subsets were quantified in the spleen and liver from female and male $L y 6 e^{\Delta \mathrm{HSC}}$ and $L y 6 e^{\mathrm{f} / / \mathrm{ll}}$ mice $5 \mathrm{~d}$ after injection with PBS or the intermediate dose of MHV (Extended Data Fig. 9). In infected male mice, haematopoietic Ly6e protected hepatic B cells and recruited natural killer cells, dendritic cells, macrophages and neutrophils, but had no influence on $\mathrm{CD}^{+}$ T cell recruitment (Extended Data Fig. 10a). Haematopoietic Ly6e in infected female mice protected hepatic B cells and $\mathrm{CD}^{+} \mathrm{T}$ cells and recruited natural killer cells (Fig. 4d). Multiple splenic cell populations were also altered with MHV infection in both male and female mice (Fig. 4e and Extended Data Fig. 10b). The depletion of immune cell populations in $L y 6 e^{\Delta \mathrm{HSC}}$ organs was MHV dependent, as cell numbers were similar between PBS-injected $L y 6 e^{\Delta \mathrm{HSC}}$ and $L y 6 e^{\mathrm{f} / \mathrm{fl}}$ mice of both sexes.

To determine whether the loss of immune cells in MHV-infected $L y 6 e^{\Delta \mathrm{HSC}}$ mice correlates with increased permissiveness to infection, we assessed MHV infection in splenocytes cultured from $L y 6 e^{\Delta \mathrm{HSC}}, L y 6 e^{\mathrm{fl} / \mathrm{fl}}$ and Ifnar ${ }^{-/-}$mice. In $L y 6 e^{\mathrm{fl} / \mathrm{fl}}$ splenocyte cultures, MHV infected macrophages, neutrophils, dendritic cells and $\mathrm{B}$ cells, but not $\mathrm{CD} 4^{+}$or $\mathrm{CD} 8^{+} \mathrm{T}$ cells, as previously reported (Fig. 4f,g) ${ }^{26}$. Strikingly, B cells from both male and female $L y 6 e^{\Delta \mathrm{HSC}}$ mice were highly susceptible to MHV infection compared with B cells from $L y 6 e^{\mathrm{f} / / \mathrm{fl}}$ mice (Fig. 4h,i). Antiviral protection from $\mathrm{MHV}$ was probably conferred by constitutive Ly6e expression, as B cells from Ifnar ${ }^{-1-}$ mice showed similar resistance to MHV to cells from $L y 6 e^{\mathrm{f} / / \mathrm{fl}}$ mice. In female mice, only neutrophils from $L y 6 e^{\Delta \mathrm{HSC}}$ mice were more susceptible to MHV infection when compared with cells from Ifnar ${ }^{-1}$ but not Ly6 $e^{\mathrm{f} / \mathrm{fl}}$ mice (Extended Data Fig. 10c). Dendritic cells and macrophages from male $L y 6 e^{\Delta \mathrm{HSC}}$ mice were also more susceptible to MHV infection than respective cells from $L y 6 e^{\mathrm{t} / / \mathrm{ll}}$ mice (Extended Data Fig. 10d). Surprisingly, no other cell type showed a strong Ly6e-dependent susceptibility to MHV infection.

Together, our data show an important role for Ly6e in immune cell-mediated control of $\mathrm{CoV}$ infection. Our observation of higher splenic viral burden and infection-associated alterations in hepatic and splenic cellular subsets indicates that mortality may be due to viral pathogenesis that exceeds the ability of the immune system to control the infection. Notably, we observed MHV-induced loss of three classes of cells in $L y 6 e^{\Delta \mathrm{HSC}}$ mice: (1) cells that are not permissive to the virus ( $\mathrm{CD} 4^{+} \mathrm{T}$ cells); (2) cells that are permissive to $\mathrm{MHV}$ but do not demonstrate Ly6e knockout-dependent infection (natural killer cells); and (3) cells that are permissive to MHV in a Ly6e knockout-dependent manner (B cells, neutrophils, macrophages and dendritic cells). The increased susceptibility and reduction of Ly6e-deficient B cells suggest that lymphocytes may be key for restricting $\mathrm{MHV}$ replication and may possibly participate in downstream immune responses.

In conclusion, we identified LY6E as a $\mathrm{CoV}$ restriction factor that limits CoV entry and protects the host from severe viral disease. Our findings are striking given that LY6E has been primarily

Fig. 3 | Ly6 $\mathrm{e}^{\Delta \mathrm{HSC}}$ mice are more susceptible to MHV. a,b, Female $L y 6 \mathrm{e}^{\mathrm{fl} / \mathrm{fl}}$ and $L y 6 \mathrm{e}^{\Delta \mathrm{HSC}}$ mice were injected with PBS or 50,000 p.f.u. MHV-A59 and monitored for survival (a) and weight loss (b). c-n, Mice were assessed at 3 (c-h) or 5 d post-infection with 50,000 p.f.u. MHV-A59 (i-n) for serum ALT (c and $\mathbf{i}$ ), viral titres in the liver ( $\mathbf{d}$ and $\mathbf{j}$ ) and spleen (e and $\mathbf{k}$ ), liver necrosis ( $\mathbf{f}$ and $\mathbf{I}$ ) and inflammation ( $\mathbf{g}$ and $\mathbf{m}$ ). Images of liver sections demonstrating necrosis inflammation are shown in $\mathbf{h}$ and $\mathbf{n}$. In $\mathbf{a}$ and $\mathbf{b}, n=13$ for days 0-14 (for $L y 6 \mathrm{e}^{\mathrm{fl} / \mathrm{fl}}$ ), and $n=11$ for days $0-3, n=10$ for days $4-5, n=5$ for day 6 and

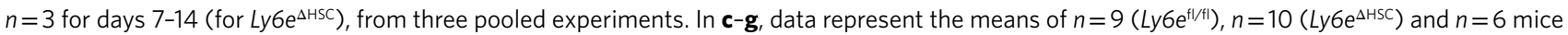
(PBS), from two pooled experiments. The images in $\mathbf{h}$ are representative of the same cohorts. In $\mathbf{i}-\mathbf{m}$, data represent the means of $n=9\left(\right.$ Ly $\left.6 e^{f l / f l}\right), n=7$ $\left(\right.$ Ly $6 \mathrm{e}^{\Delta \mathrm{HSC}}$ ) and $n=6$ mice (PBS), from two pooled experiments. Images in $\mathbf{n}$ are representative of the same cohorts. In $\mathbf{h}$ and $\mathbf{n}$, scale bars are $500 \mu M(4 \times)$ and $100 \mu \mathrm{M}(20 \times)$. Statistical significance was determined by two-sided Mantel-Cox test (a), two-tailed unpaired Student's $t$-test with Welch's correction (c-e and $\mathbf{i}-\mathbf{k})$ and two-tailed Mann-Whitney $U$-test $(\mathbf{f}, \mathbf{g}, \mathbf{I}$ and $\mathbf{~ m})$. Data are presented as means \pm s.e.m. (b) or s.d. (c-g and $\mathbf{i}-\mathbf{m})$. $P$ values: ${ }^{\star \star \star} P=0.0002$ (a); ${ }^{\star \star} P=0.0031(\mathbf{c}) ;{ }^{\star \star \star \star} P=5.759 \times 10^{-7}(\mathbf{e}) ;{ }^{\star \star} P=0.0054(\mathbf{g}) ;{ }^{\star} P=0.0430(\mathbf{i}) ;{ }^{\star \star} P=0.0094(\mathbf{k}) ;{ }^{\star \star} P=0.0072(\mathbf{I}) ;$ and ${ }^{\star \star \star \star} P=8.741 \times 10^{-5}(\mathbf{m})$. 
associated with an enhancing phenotype in which LY6E promotes entry of multiple viruses ${ }^{11-13}$. However, our data clearly expand the role of LY6E during CoV infection and establish a novel function in protecting the host immune cell compartment. Determining the precise molecular mechanism underlying how LY6E inhibits
$\mathrm{CoV}$ spike protein-mediated membrane fusion will advance our understanding of cellular antiviral defences against these important human pathogens. Antiviral membrane fusion inhibitors have been successfully implemented for the treatment of HIV-1 infection ${ }^{30}$. A therapeutic approach mimicking the mechanism of action of LY6E
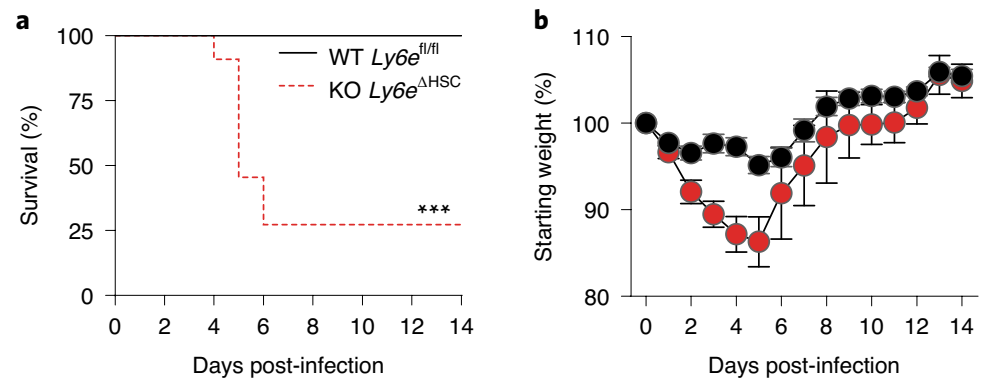

- WT $L y 6 e^{\mathrm{fl} / \mathrm{fl}}$

$\mathrm{KO} L y 6 e^{\Delta \mathrm{HSC}}$
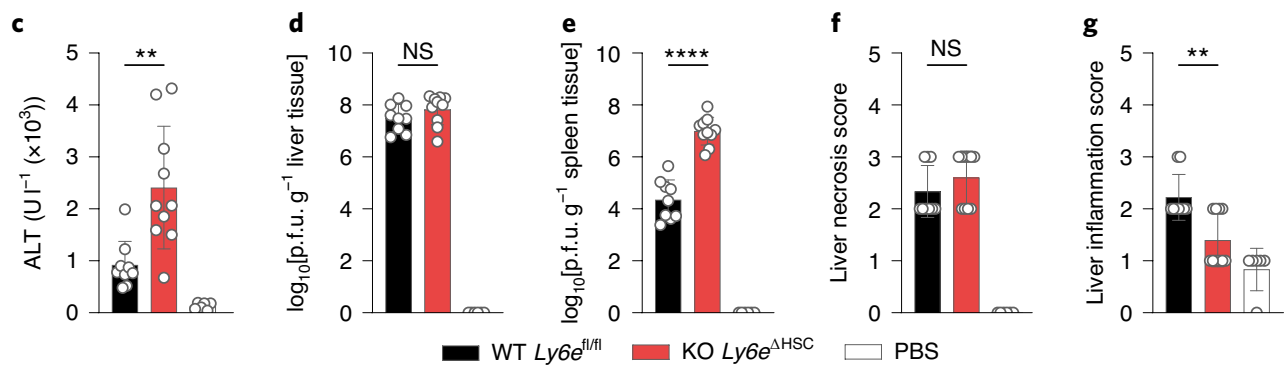

h

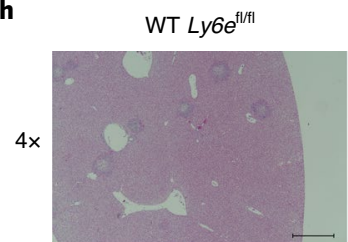

$\mathrm{KO} L y G e^{\Delta \mathrm{HSC}}$
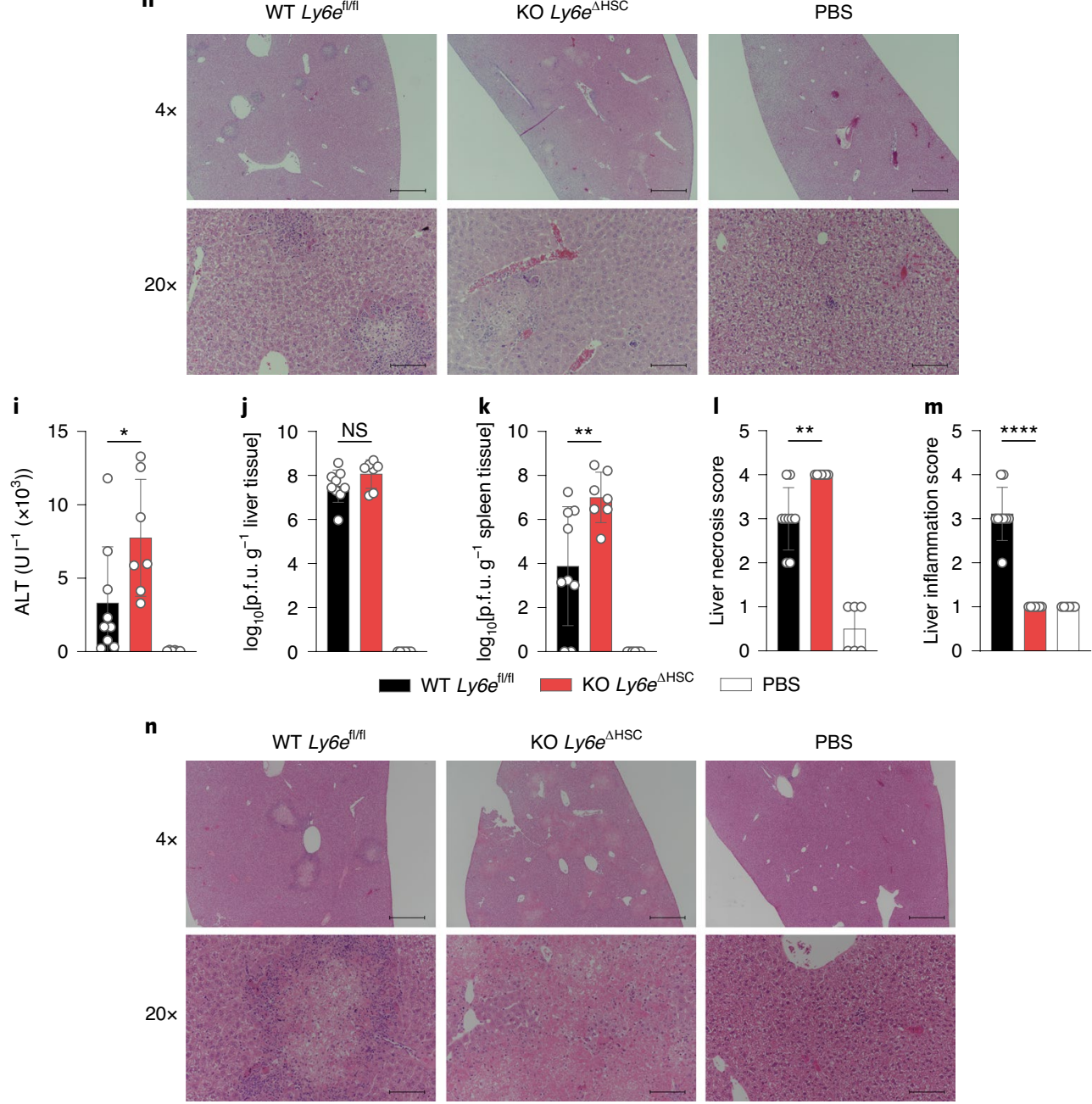


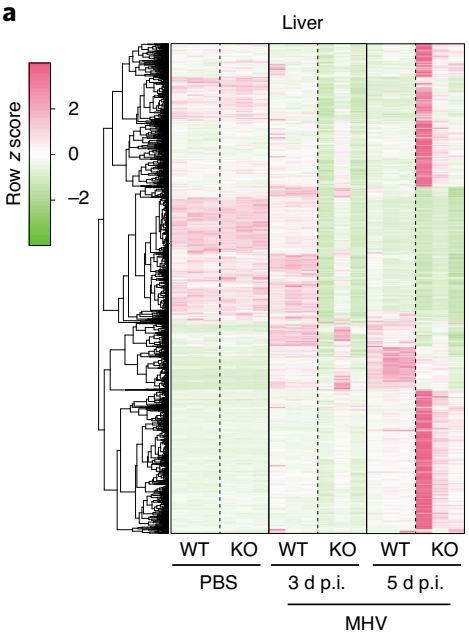

b

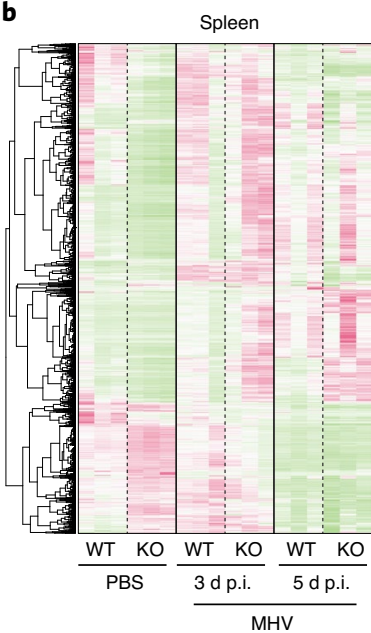

c

Response to growth factor Cell differentiation Regulation of intracellular

signal transduction
Growth

Wound healing Circulatory system

Chemotaxis

Immune response

Response to virus

Response to IFN- $\gamma$

Metabolic process

Small-molecule metabolic process

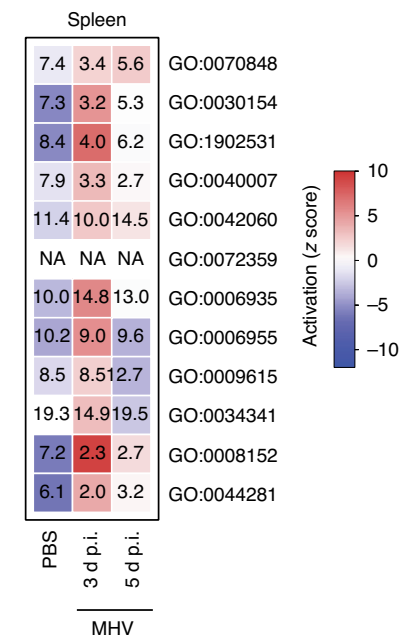

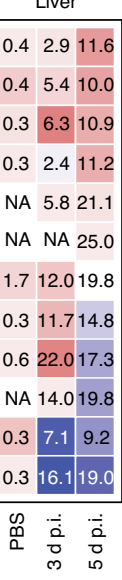

MHV d
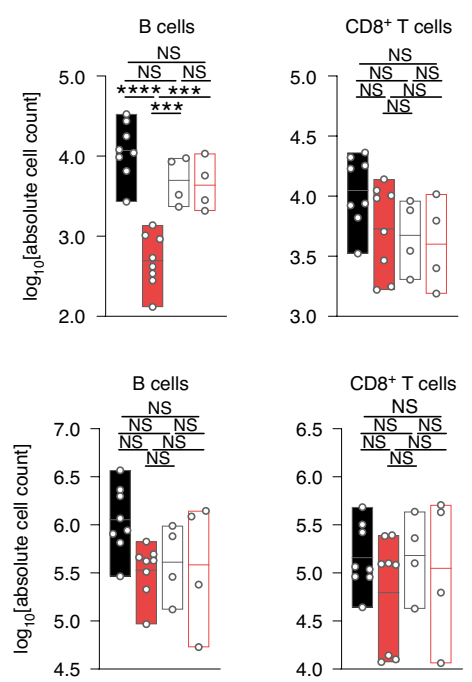

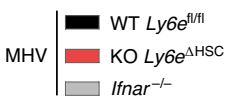

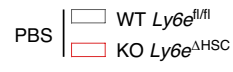
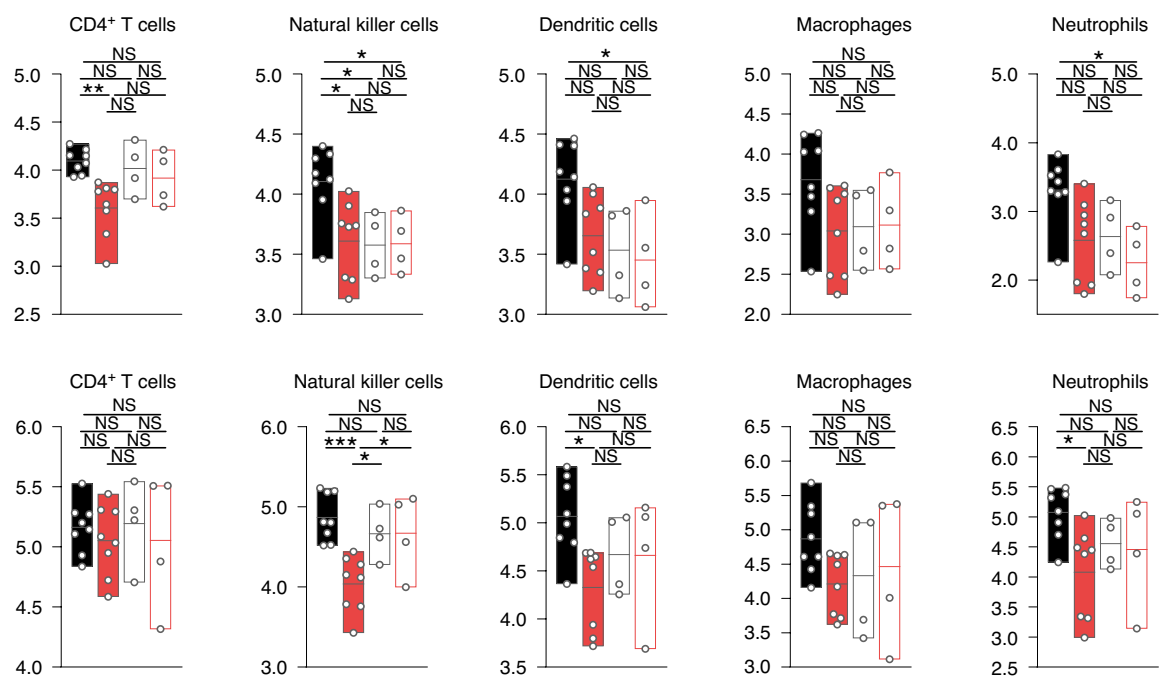

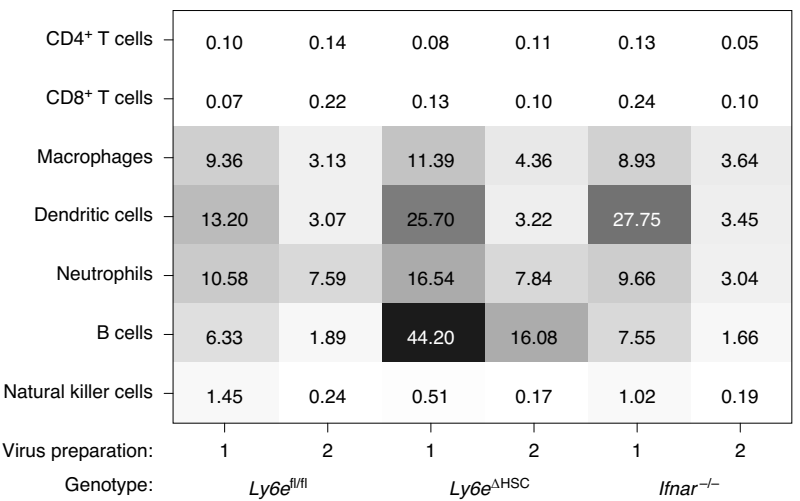

g

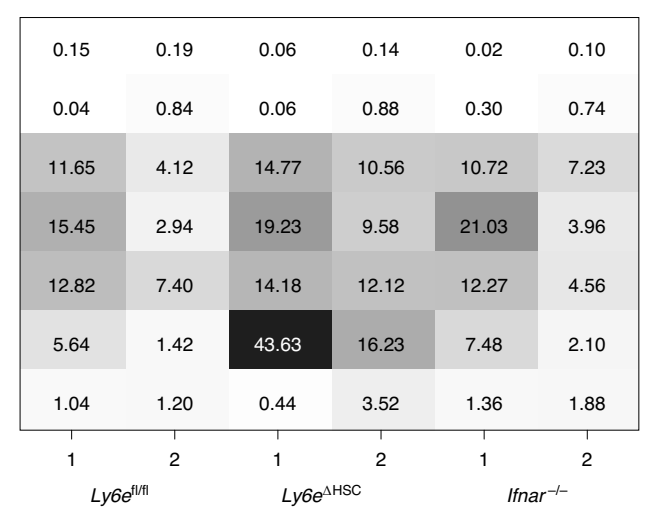

h
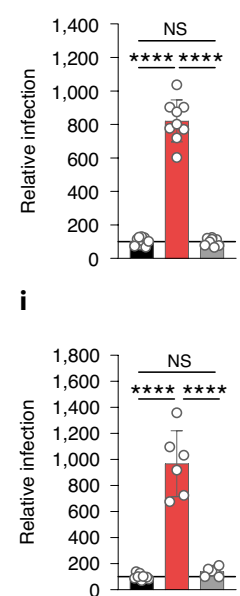

could provide a first line of defence against novel emerging $\mathrm{CoV}$ infections. Furthermore, additional in vivo work will be needed to delineate which Ly6e-expressing immune cells protect mice from $\mathrm{MHV}$, and for assessing the role of Ly6e during the pathogenesis of medically relevant human CoVs such as SARS-CoV, MERS-CoV and SARS-CoV-2.

\section{Methods}

Viral infection assays. For HCoV-229E, $1.5 \times 10^{5}$ stable LY6E-expressing or control cells were seeded in a 12-well plate and infected with $\mathrm{HCoV}-229 \mathrm{E}$ in a serial dilution. Cells were incubated for $2 \mathrm{~h}$ at $33^{\circ} \mathrm{C}$, then viral supernatant was removed and an overlay of 1:1 Avicel (2.4\%) (Avicel RC-581NF) and $2 \times$ Dulbecco's modified Eagle medium (DMEM), supplemented with $10 \%$ foetal bovine serum (FBS) and $100 \mathrm{IU} \mathrm{ml}^{-1}$ penicillin (Gibco) $/ 100 \mu \mathrm{g} \mathrm{ml}^{-1}$ streptomycin (Gibco) 
Fig. 4 | Haematopoietic Ly6e protects against MHV-induced alterations in the liver and spleen. a-c, Transcriptomic analyses from female $L y 6 e^{f / f l}$ (wild-type) and $L y 6 e^{\Delta H S C}$ (knockout) mice. In $\mathbf{a}$ and $\mathbf{b}$, heatmaps display significant changes (mean reads per kilobase of transcript per million mapped reads $>0.5$; fold change $>2$; false discovery rate $\leq 0.05$ ) in the liver (a) and spleen $(\mathbf{b})$. The dendrograms use normalized read data (row $z$ score) clustered with the complete linkage method employing Spearman's rank correlation distance measurement. In c, a pathway analysis of the knockout versus the wild type is shown. Upregulated (red) and downregulated pathways (blue) are indicated by activation z score. The numbers show significantly dysregulated genes as the percentage of the total gene number included in the pathway. $\mathbf{d}, \mathbf{e}$, Immune cell counts from the liver (d) and spleen (e) of female mice infected with 5,000 p.f.u. MHV-A59, as measured at 5 d post-infection. $\mathbf{f}, \mathbf{g}$, Heatmaps of the average MHV-GFP infectivity of cultured splenocytes from female (f) and male mice ( $\mathbf{g}$ ) with two independent viral preparations shown. h,i, MHV-GFP infection of splenic B cells from females (h) and males (i), normalized to average (line at 100) of $L y 6 \mathrm{e}^{\mathrm{fl} / \mathrm{fl}}$ mice. In $\mathbf{a}-\mathbf{c}, n=3$. In $\mathbf{d}$ and $\mathbf{e}, n=8 \mathrm{MHV}$-injected mice and $n=4$ PBS-injected mice, from two pooled

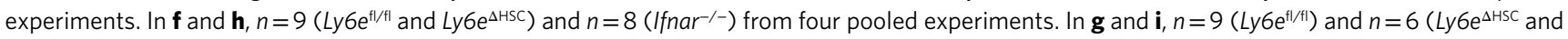
Ifnar ${ }^{-1-}$ ). Significance in $\mathbf{d}, \mathbf{e}, \mathbf{h}$ and $\mathbf{i}$ was determined by one-way ANOVA with Tukey's multiple comparisons test. For the box plots, centre lines indicate means, and upper and lower bounds, respectively, indicate maximum and minimum replicate values ( $\mathbf{d}$ and $\mathbf{e})$. Error bars represent s.d. (h and $\mathbf{i})$. $P$ values (from left to right): ${ }^{\star \star \star \star} P=4.242 \times 10^{-7},{ }^{\star \star \star} P=8.902 \times 10^{-4},{ }^{\star \star \star} P=4.581 \times 10^{-4},{ }^{\star \star} P=0.0030,{ }^{\star} P=0.0436,{ }^{\star} P=0.0381,{ }^{\star} P=0.0148,{ }^{\star} P=0.237$ and ${ }^{\star} P=0.0173(\mathbf{d}) ;{ }^{* \star} P=8.395 \times 10^{-4},{ }^{\star} P=0.0414,{ }^{\star} P=0.0439,{ }^{\star} P=0.0233$ and ${ }^{\star} P=0.0295$ (e); ${ }^{\star \star \star \star} P=1.1 \times 10^{-14}$ and ${ }^{\star \star * \star} P=1.2 \times 10^{-14}(\mathbf{h})$; and ${ }^{\star * \star \star} P=1.1416 \times 10^{-9}$ and ${ }^{\star * \star *} P=1.0469 \times 10^{-8}$ (i). GO, Gene Ontology; NA, not available; p.i., post-infection.

(penicillin-streptomycin) was added. Cells were incubated for $3 \mathrm{~d}$ at $33^{\circ} \mathrm{C}$ before medium was removed. Cells were washed and stained with crystal violet (SigmaAldrich), and p.f.u. values were calculated.

For $\mathrm{HCoV}$-OC43, $5.0 \times 10^{4}$ stable LY6E-expressing or control cells were seeded in a 24 -well plate and infected at $33^{\circ} \mathrm{C}$ for $1 \mathrm{~h}$ with $\mathrm{HCoV}-\mathrm{OC} 43$ $(($ multiplicity of infection $(\mathrm{MOI})=1)$. The virus was aspirated and $10 \% \mathrm{FBS} / 1 \times$ non-essential amino acids/ $1 \times$ penicillin-streptomycin/RPMI (cRPMI) was added back to the cells. At $24 \mathrm{~h}$ post-infection, cells were dissociated using Accumax (Sigma-Aldrich), fixed in 1\% paraformaldehyde (PFA), permeabilized per the manufacturer's protocol (BD Cytofix/Cytoperm), and stained for nucleoprotein (1:500) and a goat anti-mouse Alexa Fluor 488-conjugated secondary antibody $(1: 2,000)$. Infection was analysed by flow cytometry.

For MERS-CoV, SARS-CoV and SARS-CoV-2, $1 \times 10^{4}$ stable LY6E-expressing or control cells were seeded in a 96 -well plate and infected at $37^{\circ} \mathrm{C}$ in a serial dilution assay. At 3-4 d post-infection, the supernatant was removed and cells were stained with crystal violet (Sigma-Aldrich). The cytopathic effect was determined upon visual inspection, and the median tissue culture infectious dose $\left(\mathrm{TCID}_{50}\right)$ per $\mathrm{ml}$ was calculated according to the Reed-Muench method.

For SARS-CoV-2 infection in Huh7.5 cells, $5 \times 10^{4}$ stable LY6E-expressing or control cells were seeded in a 24 -well plate and infected at $37^{\circ} \mathrm{C}$ for $1 \mathrm{~h}$. At $24 \mathrm{~h}$ post-infection, cells were harvested, permeabilized and analysed as described for $\mathrm{HCoV}-\mathrm{OC} 43$, with the exception of $4 \% \mathrm{PFA}$ for fixation, and staining for double-stranded RNA (dsRNA; 1:10,000) and a goat anti-mouse Alexa Fluor 488-conjugated secondary antibody $(1: 1,000)$.

For MHV-Gluc, $1 \times 10^{5}$ stable LY6E-expressing or control cells were seeded in a 24 -well plate and infected with $\mathrm{MHV}$-Gluc $(\mathrm{MOI}=0.1)$ at $37^{\circ} \mathrm{C}$. After $2 \mathrm{~h}$, virus inoculum was removed, cells were washed with PBS and cRPMI was added back. At $24 \mathrm{~h}$ post-infection, the cell culture supernatant was harvested, and Gluc activity was measured using a Pierce Gaussia Luciferase Glow Assay Kit (Thermo Fisher Scientific) and a plate luminometer (EnSpire 2300 Multilabel reader; Perkin Elmer). For testing of the virus panel against LY6E, $1 \times 10^{4}$ stable LY6E-expressing or control Huh7.5 cells were seeded in a 96-well plate. Cells were infected with the following viruses and harvested after the indicated times: $\mathrm{HCoV}$ $229 \mathrm{E}(\mathrm{MOI}=0.001 ; 72 \mathrm{~h}), \mathrm{HCV}-Y$ pet $(\mathrm{MOI}=1 ; 72 \mathrm{~h}), \mathrm{CHIKV}-\mathrm{GFP}(\mathrm{MOI}=0.005$; $24 \mathrm{~h})$, hPIV-3-GFP $(\mathrm{MOI}=0.015 ; 24 \mathrm{~h})$, RSV-GFP $(\mathrm{MOI}=1.5 ; 24 \mathrm{~h})$, SINV-GFP $(\mathrm{MOI}=0.1 ; 24 \mathrm{~h}), \mathrm{VEEV}-\mathrm{GFP}(\mathrm{MOI}=0.0075 ; 24 \mathrm{~h}), \mathrm{WNV}-\mathrm{GFP}(\mathrm{MOI}=1.5 ; 24 \mathrm{~h})$, Zika virus $(\mathrm{ZIKV})$ PRVABC59 $(\mathrm{MOI}=0.01 ; 48 \mathrm{~h})$, yellow fever virus $17 \mathrm{D}$-venus $(\mathrm{MOI}=0.01 ; 48 \mathrm{~h})$ and DENV-GFP $(\mathrm{MOI}=0.05 ; 72 \mathrm{~h})$. At the indicated time points, cells were fixed with $4 \%$ PFA/PBS. ZIKV-infected cells were stained for viral E protein (1:500) and an Alexa Fluor 488-conjugated goat anti-mouse secondary antibody (1:1,000). Images were acquired with a fluorescence microscope and analysed using ImageXpress Micro XLS (Molecular Devices).

SARS-CoV-2 infection of ACE2-expressing cells. Approximately $3 \times 10^{4} \mathrm{Huh} 7.5$ cells were plated in eight-well chamber slides. Cells were infected in a low volume with $0.5 \mathrm{MOI}$ SARS-CoV-2 for $1 \mathrm{~h}$ at $37^{\circ} \mathrm{C}$, incubated for $9 \mathrm{~h}$ more at full volume and then fixed in $3.7 \%$ formaldehyde. Cells were permeabilized, stained for dsRNA (1:500; see the Supplementary Information 'Antibodies for immunofluorescence and flow cytometry' section) and imaged as previously described, except mounting was performed with Vectashield with 4',6-diamidine-2' -phenylindole (DAPI;

H-1200; Vector Labs) ${ }^{31}$. Seven images were acquired for each condition. Images were processed using ImageJ by equally adjusting the minimum brightness to normalize the background and measuring the mean intensity of the entire dsRNA image. Nucle were enumerated using ImageJ, using the threshold, watershed and analyze particles features. The mean fluorescence intensity per nucleus was determined by dividing the mean intensity of the GFP channel by the total number of nuclei in the field.

HCoV-229E-Rluc infection assay of knockout cells. For infection assays, $1 \times 10^{5}$ target cells were seeded in a 24 -well plate $1 \mathrm{~d}$ before infection. Cells were infected with HCoV-229E-Rluc (MOI $=0.1$ ) in OptiMEM (Gibco) for $2 \mathrm{~h}$ at $33^{\circ} \mathrm{C}$. Cells were washed $1 \times$ with $\mathrm{PBS}$, and $10 \% \mathrm{FBS} / 1 \times$ non-essential amino acids $/ 1 \times$ penicillin-streptomycin/DMEM (cDMEM) was added back. Cells were incubated at $33^{\circ} \mathrm{C}$ for $24 \mathrm{~h}$, then washed with PBS and lysed using the Renilla Luciferase Assay System kit (Promega). Renilla luciferase (Rluc) activity was measured using a plate luminometer (EnSpire 2300 Multilabel reader; Perkin Elmer). For the reconstitution with CRISPR-resistant LY6E, $2.5 \times 10^{4}$ cells were seeded in a 24 -well plate. At $1 \mathrm{~d}$ post-seeding, cells were either left untransduced or transduced with a lentiviral vector encoding for CRISPR-resistant LY6E or the empty control. At $48 \mathrm{~h}$ post-transduction, cell lysates were either infected with HCoV-229E-Rluc $(\mathrm{MOI}=0.1)$ for $24 \mathrm{~h}$ as described above or harvested for western blot.

VSV pseudoparticles. Pseudotyping of $\mathrm{VSV}^{\star} \Delta \mathrm{G}$ (Fluc) was performed as previously described ${ }^{32}$. Briefly, $6 \times 10^{5} 293 \mathrm{LTV}$ cells were seeded in a six-well plate and transfected using Lipofectamine 2000 (Invitrogen), which was complexed with DNA plasmids driving the expression of either VSV-G protein (positive control), the respective $\mathrm{CoV}$ spike proteins or the fluorophore mCherry (negative control). Expression vectors for VSV (serotype Indiana) glycoprotein (VSV-G; GenBank accession number NC_001560), HCoV-229E S (pCAGGS-229E S; GenBank accession number X16816), MERS-CoV S (pCAGGS-MERS S; GenBank accession number JX869059, with a silent point mutation (C4035A, removing internal XhoI)) and SARS-CoV S (pCAGGS-SARS S; GenBank accession number: AY291315.1, with two silent mutations (T2568G and T3327C)) have been described previously ${ }^{33,34}$. The expression plasmid for SARS-CoV-2 was generated as follows. The coding sequence of a synthetic, codon-optimized (for human cells) SARS-CoV-2 DNA (GeneArt Gene Synthesis; Thermo Fisher Scientific) based on the publicly available protein sequence in the National Center for Biotechnology Information database (NCBI reference sequence YP_009724390.1) was PCR amplified and cloned into the pCG1 expression vector between the BamHI and XbaI restriction sites. The MERS-CoV spike cleavage mutants have been described before $^{20}$. pCAGGS_mCherry was generated upon cloning of the mCherry reporter gene into the pCAGGS expression vector (the primer sequences and cloning procedure are available upon request). At $20 \mathrm{~h}$ post-transfection, cells were infected with VSV-G-trans-complemented $\mathrm{VSV}^{*} \Delta \mathrm{G}$ (FLuc) $(\mathrm{MOI}=5)$ for $30 \mathrm{~min}$ at $37^{\circ} \mathrm{C}$, washed with PBS and further incubated for $1 \mathrm{~h}$ in CDMEM that was supplemented with monoclonal antibody I1 (ATCC, 1:100) - a neutralizing monoclonal antibody directed to the VSV-G protein. Cells were then washed and CDMEM was added back. Viral supernatant was harvested at $16-24 \mathrm{~h}$ post-infection. Cellular debris were removed by centrifugation $\left(3,000 \mathrm{~g}\right.$ for $10 \mathrm{~min}$ ) and used to inoculate $2 \times 10^{4}$ target cells in a 96-well plate (six technical replicates). Cells were incubated for $16-18 \mathrm{~h}$ at $37^{\circ} \mathrm{C}$ before Fluc activity in cell lysates was detected using a plate luminometer (EnSpire 2300 Multilabel reader; Perkin Elmer) and the Bright-Glo Luciferase Assays System (Promega). Experiments with pseudotyped SARS-CoV and SARS-CoV-2 were performed as previously described ${ }^{20}$.

Cell-cell fusion assay. The cell-cell luciferase/GFP fusion assay has been described before, with slight modifications ${ }^{35}$. Briefly, $6 \times 10^{5} 293$ LTV cells were transfected with plasmids encoding CoV spike proteins (for the constructs, please refer to VSV pseudoparticles; pCAGGS-HCoV-229E, pCAGGS-MERS-CoV, pCAGGS-SARS-CoV and pCAGGS-SARS-CoV-2) together with a split-luciferase/ split-GFP construct (Rluc8155-156; DSP1-7). The empty expression plasmid (pCAGGS-mCherry), as well as a construct encoding for VSV-G, served as the negative and positive control, respectively. Some $2 \times 10^{5}$ stable LY6E-expressing or empty control Huh7 or VeroE6 cells were transfected using Lipofectamine 2000 (Thermo Fisher Scientific) with a plasmid encoding the complementary fragment of the split-luciferase/split-GFP protein (Rluc8155-156; DSP8-11). Approximately $30 \mathrm{~h}$ post-transfection, both cell populations were dissociated (TrypLE Express; Gibco) and counted, and equal cell numbers $\left(2 \times 10^{4}\right.$ cells each) were co-cultured for $16-20 \mathrm{~h}$ at $37^{\circ} \mathrm{C}$. Cells were rinsed with PBS and fixed using $4 \%$ PFA in PBS. 
Four images were acquired using an EVOS FL Auto 2 imaging system equipped with a $4 \times$ air objective $(\mathrm{NA}=0.13)$ and stitched using the integrated software (Image J 2.0.0-rc-69/1.52p; Java 1.8.0_172 (64 bits); Windows 10, 10.0). Images were processed by applying background subtraction (rolling ball; size $=25$ pixels) and measuring the mean intensity of the entire image.

Syncytia formation assay. Cells expressing LY6E or empty control were infected with VSV ${ }^{\star} \Delta \mathrm{G}$ (MERS S) or VSV ${ }^{\star} \Delta \mathrm{G}(229 \mathrm{E} \mathrm{S})$ at an MOI of 0.01 . At $20 \mathrm{~h}$ post-infection, the cells were fixed with $3 \%$ PFA/PBS and the nuclei were stained with DAPI (Sigma-Aldrich; 1:10,000). An inverted fluorescence microscope (Zeiss) was used to determine the percentage area covered by syncytia.

For the heterologous cell-cell fusion assay, BHK-21 cells were infected with $\mathrm{VSV}^{\star} \Delta \mathrm{G}(\mathrm{CoV}$ S) at an MOI of 1 . After $2 \mathrm{~h}$, the cells were treated with trypsin/ EDTA (Life Technologies) and resuspended in DMEM supplemented with 5\% FBS $\left(2 \times 10^{4}\right.$ cells per $\left.\mathrm{ml}\right)$. The infected BHK-21 cell suspension $(500 \mu \mathrm{l})$ was seeded into 24-well cell culture plates along with LY6E- or empty control-expressing Huh7 $\left(1 \times 10^{4}\right.$ cells). Cell co-cultures were incubated for $7 \mathrm{~h}$ at $37^{\circ} \mathrm{C}$, fixed with $3.6 \%$ formaldehyde diluted in PBS (Grogg Chemie) and stained with DAPI. The percentage area covered by syncytia was calculated as above.

Mice. Ly6 $\mathrm{e}^{\mathrm{tm} 1 \mathrm{a}}$ embryonic stem cells were obtained from the EUCOMM consortium $^{36}$ and microinjected into C57BL/6J blastocysts by the University of Texas Southwestern Medical Center (UTSW) Transgenic Technology Center. Chimeric mice with germline transmission were bred to obtain Ly6 $e^{\mathrm{tm} 1 \mathrm{a} /+}$ offspring. Ly6 $e^{\mathrm{tm} 1 \mathrm{a} /+}$ mice were crossed with FLPe-expressing mice (B6N.129S4-Gt(ROSA)26Sor ${ }^{\mathrm{tm} 1(\mathrm{FLP1}) \mathrm{Dym}} / \mathrm{J}$; 16226; The Jackson Laboratory) to obtain $L y 6 e^{\mathrm{f} / \mathrm{+}}$ offspring, which were bred to homozygosity. Conditional $L y 6 e^{\mathrm{f} / \mathrm{fl}}$ mice were

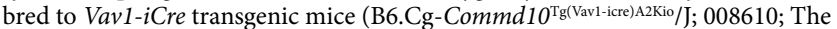
Jackson Laboratory) to obtain $L y 6 e^{\Delta \mathrm{HSC} /+}\left(L y 6 e^{\mathrm{fl} /+} ;\right.$ Vav1-iCre $)$ offspring. Ly6 $e^{\Delta \mathrm{HSC} /+}$ mice were bred to obtain $L y 6 e^{\Delta \mathrm{HSC}}\left(L y 6 e^{\mathrm{f} / / \mathrm{f}} ; \mathrm{Vav} 1-i \mathrm{Cr} e\right)$ offspring, which harbour a deletion of exon 3 and 4 in HSCs. Experimental animals were obtained by crossing $L y 6 e^{\Delta \mathrm{HSC}}$ and $L y 6 e^{\mathrm{f} / / \mathrm{fl}}$ mice. Littermates were used for the majority of experiments when possible; otherwise, mice of a similar age (within 2 weeks) were used. Sample size was chosen based on published studies, and no randomization or blinding was performed aside from the scoring of liver histology. Genotype was confirmed by PCR of genomic DNA in house or outsourced to Transnetyx. Ablation of Ly6e was confirmed by quantitative PCR in immune cells from the spleen, liver or bone marrow. Ifnar ${ }^{-1}$ mice on a C57BL/6J background were a kind gift from $\mathrm{N}$. Yan (UTSW). Animal studies were carried out in specific pathogen-free barrier facilities managed and maintained by the UTSW Animal Resource Center. Facilities were maintained at an acceptable range of $68-79^{\circ} \mathrm{F}$ at a humidity of $30-70 \%$ on a $12 \mathrm{~h}$ dark $/ 12 \mathrm{~h}$ light cycle. All procedures used in this study complied with federal and institutional guidelines enforced by the UTSW Institutional Animal Care and Use Committee and were granted institutional approval after veterinary and committee review.

In vivo infection, viral titres, liver ALT and liver histology. Female and male mice (6-12 weeks old) were injected intraperitoneally with MHV-A59 diluted in PBS to the indicated titres, or PBS for a mock infection control. Unless otherwise indicated, $L y 6 e^{\mathrm{fl} / \mathrm{fl}}$ mice were used for mock infection controls. All infected mice were monitored daily for weight and mortality. Animals that lost more than $20 \%$ of their original body weight were euthanized per Institutional Animal Care and Use Committee guidelines.

Viral titres in liver and spleen were determined from frozen organs after weighing, homogenization and plaque assay on L929 cells. ALT was measured in fresh, unfrozen serum using VITROS MicroSlide Technology by the UTSW Mouse Metabolic Core. Livers were fixed in $10 \%$ neutral buffer formalin, embedded in paraffin, sectioned at $5 \mu \mathrm{M}$ and stained with haematoxylin and eosin. Slides were analysed by an independent pathologist (UTSW Animal Resource Center) who was blinded to the experimental conditions. A numerical score was assigned for the degree of inflammation and degree of necrosis for each liver. Inflammatory cell infiltration was scored using the following criteria: $0=$ none, $1=$ minimal, $2=$ mild $3=$ moderate and $4=$ marked. The necrosis score was defined by the percentage of necrosis $(0=$ none, $1=<2 \%, 2=2-20 \%, 3=21-40 \%$ and $4=>40 \%)$.

Primary cell preparation for flow cytometry. Primary cells were isolated from female and male mice (6-15 weeks old). All primary cells were maintained in $10 \% \mathrm{FBS} / 10 \mathrm{mM} \mathrm{HEPES} / 1 \mathrm{mM}$ sodium pyruvate $/ 2 \mathrm{mM}$ L-glutamine/1× penicillin-streptomycin/RPMI (cRPMI2) unless otherwise indicated.

Primary BMDMs were prepared as described previously ${ }^{37}$. Viable cells were quantified using trypan blue exclusion. BMDMs were plated at $2.5 \times 10^{4}$ cells per well in non-treated 24-well tissue culture plates. Cells were infected the next day with MHV-A59-GFP $(\mathrm{MOI}=0.1)$ and isolated $6 \mathrm{~h}$ post-infection for analysis by flow cytometry.

Splenocytes were prepared by mashing whole spleens against a $70-\mu \mathrm{M}$ cell strainer. Red blood cells were removed using RBC lysis buffer (Tonbo Biosciences). Viable cells were quantified using trypan blue exclusion. For in vitro infection, splenocytes were plated at $1 \times 10^{6}$ cells per well in non-treated six-well tissue culture plates and immediately infected with MHV-A59-GFP $(\mathrm{MOI}=1)$ for
$2 \mathrm{~h}$ before increasing the media volume fivefold. Infected cells were isolated $8 \mathrm{~h}$ post-infection, stained with a fluorescent viability dye (Ghost Dye Violet 450; 1:1,000; Tonbo Biosciences) and fixed in 1\% PFA/PBS. The next day, fixed cells were treated with anti-CD16/CD32 (1:100; Tonbo Biosciences), then stained with antibodies that recognize surface lineage markers and analysed by flow cytometry.

Livers were perfused by PBS injection into the inferior vena cava and out of the portal vein. Blanched livers were minced with sterile scissors and mashed against a $70-\mu \mathrm{M}$ cell strainer. Hepatocytes and large debris were pelleted at $60 \mathrm{~g}$ for $1 \mathrm{~min}$, at $22^{\circ} \mathrm{C}$, with no brake. Supernatants containing intrahepatic immune cell (IHICs) and residual hepatocytes were pelleted at $480 \mathrm{~g}$ for $8 \mathrm{~min}$, at $22^{\circ} \mathrm{C}$, with maximum brake, and resuspended in 37.5\% Percoll (Sigma-Aldrich)/cRPMI2. The remaining hepatocytes were separated from the IHICs by centrifugation at $850 \mathrm{~g}$ for $30 \mathrm{~min}$, at $22^{\circ} \mathrm{C}$, with no brake. Red blood cells were removed from the resulting pellet with RBC lysis buffer (Tonbo Biosciences). Viable cells were quantified using trypan blue exclusion. IHICs and splenocytes $\left(4 \times 10^{5}\right)$ from infected or mock-infected mice were stained with a fluorescent viability dye (Ghost Dye Violet 450; 1:1,000; Tonbo Biosciences), treated with anti-CD16/CD32 (1:100; Tonbo Biosciences), stained with antibodies that recognize surface lineage markers and then fixed in $1 \%$ PFA/PBS. Fixed volumes of cell suspensions were analysed by flow cytometry the next day. Absolute cell counts were determined by multiplying the final number of lineage marker-positive cells by the dilution factor used to normalize the cell counts for antibody staining.

All primary cell samples were resuspended in 3\% FBS/PBS, analysed using an S1000 Flow Cytometer with an A600 96-well plate high-throughput extension and compensated using CellCapTure software (Stratedigm). Data were analysed with FlowJo Software (Tree Star). The flow gating strategy for liver and spleen immune cells is included in Extended Data Fig. 9.

Statistical analysis. Differences in data were tested for significance using GraphPad Prism version 8.3.1 for Windows (GraphPad). For details regarding the statistical tests applied, please refer to the figure captions. $P$ values $<0.05$ were considered significant. $P$ values $>0.05$ are listed by figure in Supplementary Table 4.

Reporting Summary. Further information on research design is available in the Nature Research Reporting Summary linked to this article.

\section{Data availability}

The authors declare that the data supporting the findings of this study are available within the article and its Supplementary Information files, or are available on request. The RNA-seq data discussed in this publication have been deposited in the Gene Expression Omnibus database, https://www.ncbi.nlm.nih.gov/geo (GSE146074). The data used for scRNA-seq analysis of hAECs have been reported previously ${ }^{38}$. The data used for RNA-seq analysis of LY6E induction in hAECs after viral infection have been reported previously ${ }^{39}$. The GenBank (https://www.ncbi.nlm.nih.gov/ genbank/) accession codes for the viral gene sequences used to generate the spike protein pseudoparticles are: NC_001560 (VSV-G); X16816 (HCoV-229E S); JX869059 (MERS-CoV S); and AY291315.1 (SARS-CoV S). The NCBI Reference Sequence for SARS-CoV-2 is available via the accession code YP_009724390.1. The NCBI accession number for generating the expression plasmid for Camelus dromedarius LY6E is XM_031439745.1. Source data are provided with this paper.

Received: 6 June 2020; Accepted: 3 July 2020;

Published online: 23 July 2020

\section{References}

1. Zhu, N. et al. A novel coronavirus from patients with pneumonia in China, 2019. N. Engl. J. Med. 382, 727-733 (2020).

2. Drosten, C. et al. Identification of a novel coronavirus in patients with severe acute respiratory syndrome. N. Engl. J. Med. 348, 1967-1976 (2003).

3. Zaki, A. M., van Boheemen, S., Bestebroer, T. M., Osterhaus, A. D. \& Fouchier, R. A. Isolation of a novel coronavirus from a man with pneumonia in Saudi Arabia. N. Engl. J. Med. 367, 1814-1820 (2012).

4. Kindler, E., Thiel, V. \& Weber, F. Interaction of SARS and MERS coronaviruses with the antiviral interferon response. Adv. Virus Res. 96 219-243 (2016)

5. Corman, V. M., Muth, D., Niemeyer, D. \& Drosten, C. Hosts and sources of endemic human coronaviruses. Adv. Virus Res. 100, 163-188 (2018).

6. Wang, B. X. \& Fish, E. N. Global virus outbreaks: interferons as 1st responders. Semin. Immunol. 43, 101300 (2019).

7. Cervantes-Barragan, L. et al. Control of coronavirus infection through plasmacytoid dendritic-cell-derived type I interferon. Blood 109, 1131-1137 (2007)

8. Schoggins, J. W. Interferon-stimulated genes. What do they all do? Annu. Rev. Virol. 6, 567-584 (2019).

9. Schoggins, J. W. et al. A diverse range of gene products are effectors of the type I interferon antiviral response. Nature 472, 481-485 (2011).

10. Dittmann, M. et al. A serpin shapes the extracellular environment to prevent influenza A virus maturation. Cell 160, 631-643 (2015). 
11. Mar, K. B. et al. LY6E mediates an evolutionarily conserved enhancement of virus infection by targeting a late entry step. Nat. Commun. 9, 3603 (2018).

12. Hackett, B. A. \& Cherry, S. Flavivirus internalization is regulated by a size-dependent endocytic pathway. Proc. Natl Acad. Sci. USA 115, 4246-4251 (2018).

13. Yu, J., Liang, C. \& Liu, S. L. Interferon-inducible LY6E protein promotes HIV-1 infection. J. Biol. Chem. 292, 4674-4685 (2017).

14. Yu, J., Liang, C. \& Liu, S. L. CD4-dependent modulation of HIV-1 entry by LY6E. J. Virol. 93, e01866-18 (2019).

15. Upadhyay, G. Emerging role of lymphocyte antigen-6 family of genes in cancer and immune cells. Front. Immunol. 10, 819 (2019).

16. Hoffmann, M., Kleine-Weber, H. \& Pohlmann, S. A multibasic cleavage site in the spike protein of SARS-CoV-2 is essential for infection of human lung cells. Mol. Cell 78, 779-784 (2020).

17. Xia, S. et al. Inhibition of SARS-CoV-2 (previously 2019-nCoV) infection by a highly potent pan-coronavirus fusion inhibitor targeting its spike protein that harbors a high capacity to mediate membrane fusion. Cell Res. 30, 343-355 (2020).

18. Heald-Sargent, T. \& Gallagher, T. Ready, set, fuse! The coronavirus spike protein and acquisition of fusion competence. Viruses 4, 557-580 (2012).

19. Park, J. E. et al. Proteolytic processing of Middle East respiratory syndrome coronavirus spikes expands virus tropism. Proc. Natl Acad. Sci. USA 113, 12262-12267 (2016)

20. Kleine-Weber, H., Elzayat, M. T., Hoffmann, M. \& Pohlmann, S. Functional analysis of potential cleavage sites in the MERS-coronavirus spike protein. Sci. Rep. 8, 16597 (2018).

21. Langford, M. B., Outhwaite, J. E., Hughes, M., Natale, D. R. C. \& Simmons, D. G. Deletion of the Syncytin A receptor Ly6e impairs syncytiotrophoblast fusion and placental morphogenesis causing embryonic lethality in mice. Sci. Rep. 8, 3961 (2018).

22. Matthews, A. E. et al. Antibody is required for clearance of infectious murine hepatitis virus A59 from the central nervous system, but not the liver. J. Immunol. 167, 5254-5263 (2001).

23. Phares, T. W. et al. CD4 T cells promote CD $8 \mathrm{~T}$ cell immunity at the priming and effector site during viral encephalitis. J. Virol. 86, 2416-2427 (2012).

24. Wijburg, O. L., Heemskerk, M. H., Sanders, A., Boog, C. J. \& Van Rooijen, N. Role of virus-specific $\mathrm{CD}^{+}$cytotoxic $\mathrm{T}$ cells in recovery from mouse hepatitis virus infection. Immunology 87, 34-41 (1996).

25. Wijburg, O. L., Heemskerk, M. H., Boog, C. J. \& Van Rooijen, N. Role of spleen macrophages in innate and acquired immune responses against mouse hepatitis virus strain A59. Immunology 92, 252-258 (1997).

26. Cervantes-Barragan, L. et al. Type I IFN-mediated protection of macrophages and dendritic cells secures control of murine coronavirus infection. J. Immunol. 182, 1099-1106 (2009).

27. Weiss, S. R. \& Leibowitz, J. L. Coronavirus pathogenesis. Adv. Virus Res. 81, 85-164 (2011)

28. Eriksson, K. K., Cervantes-Barragan, L., Ludewig, B. \& Thiel, V. Mouse hepatitis virus liver pathology is dependent on ADP-ribose-1" $1^{\prime \prime}$-phosphatase, a viral function conserved in the alpha-like supergroup. J. Virol. 82, 12325-12334 (2008)

29. Karnam, G. et al. CD200 receptor controls sex-specific TLR7 responses to viral infection. PLoS Pathog. 8, e1002710 (2012).

30. Lalezari, J. P. et al. Enfuvirtide, an HIV-1 fusion inhibitor, for drug-resistant HIV infection in North and South America. N. Engl. J. Med. 348, 2175-2185 (2003)

31. Richardson, R. B. et al. A CRISPR screen identifies IFI6 as an ER-resident interferon effector that blocks flavivirus replication. Nat. Microbiol. 3, 1214-1223 (2018).

32. Torriani, G. et al. Identification of clotrimazole derivatives as specific inhibitors of arenavirus fusion. J. Virol. 93, e01744-18 (2019).

33. Gierer, S. et al. The spike protein of the emerging betacoronavirus EMC uses a novel coronavirus receptor for entry, can be activated by TMPRSS2, and is targeted by neutralizing antibodies. J. Virol. 87, 5502-5511 (2013).

34. Hoffmann, M. et al. Differential sensitivity of bat cells to infection by enveloped RNA viruses: coronaviruses, paramyxoviruses, filoviruses, and influenza viruses. PLoS ONE 8, e72942 (2013).

35. Qing, E., Hantak, M., Perlman, S. \& Gallagher, T. Distinct roles for sialoside and protein receptors in coronavirus infection. mBio 11, e02764-19 (2020).

36. Skarnes, W. C. et al. A conditional knockout resource for the genome-wide study of mouse gene function. Nature 474, 337-342 (2011).
37. Agac, D., Estrada, L. D., Maples, R., Hooper, L. V. \& Farrar, J. D. The $\beta 2$-adrenergic receptor controls inflammation by driving rapid IL-10 secretion. Brain Behav. Immun. 74, 176-185 (2018).

38. Kelly, J. N. et al. Comprehensive single cell analysis of pandemic influenza A virus infection in the human airways uncovers cell-type specific host transcriptional signatures relevant for disease progression and pathogenesis. Preprint at https://doi.org/10.1101/2020.04.03.014282 (2020).

39. V'kovski, P. et al. Disparate temperature-dependent virus-host dynamics for SARS-CoV-2 and SARS-CoV in the human respiratory epithelium. Preprint at https://doi.org/10.1101/2020.04.27.062315 (2020).

\section{Acknowledgements}

We thank the sequencing facility in Bern, the diagnostic facility of the Institute of Virology and Immunology (IVI) and the Animal Resource Center at UTSW for generously contributing reagents and infrastructure, which greatly enhanced this study. Furthermore, we are grateful to R. Pohorelsky, S. Elias and N. Garcia from the UTSW Animal Resource Center for assisting with the in vivo experiments. We are grateful to S. Locher (IVI, Bern, Switzerland) for cloning the MERS spike complementary DNA. Furthermore, we thank B. J. Bosch, M. Müller and C. Drosten for reagents and the SARS-CoV-2 virus stocks. We thank the following investigators for contributing viral molecular clones or viral stocks: P. L. Collins (respiratory syncytial virus and human parainfluenza virus type 3), I. Frolov (Venezuelan equine encephalitis virus), M. T. Heise (Sindbis virus), S. Higgs (Chikungunya virus) and the CDC (ZIKV). Finally, we thank al members (past and present) of the IVI, the Schoggins laboratory and the Rice laboratory for useful discussions. S. Pfaender was supported by the European Commission's Horizon 2020 Research and Innovation Program under Marie Skłodowska-Curie grant agreement 748627 and the Swiss National Science Foundation (SNF; grant no. 310030 173085). K.B.M. and J.W.S. were supported in part by The Clayton Foundation and The American Lung Association. J.W.S. was additionally supported by NIH grant no. AI117922 and a Burroughs Wellcome Fund 'Investigators in the Pathogenesis of Infectious Disease' award. K.B.M. was additionally supported by NIH Training Grant no. AI005284. S. Pöhlmann was supported by the Federal Ministry of Education and Research (BMBF), the RAPID Consortium and grant no. 01KI1723D. N.W.H. was supported by NIH grant no. AI132751. E.M., H.H.H., M.S. and C.M.R. were supported in part by NIH grant nos. AI091707 and AI091707-10S1 and The G. Harold and Leila Y. Mathers Charitable Foundation. R.D. was supported by the SNF (grant no. 179260). G.Z. was supported by SNF grant no. 166265. P.V. and J.N.K. were supported by the SNF (grant nos. 310030_173085 (P.V. and J.N.K.) and CRSII3_160780 (J.N.K.)). A.K. was supported by the BMBF (grant RAPID; 01KI1723A). V.T. was supported by the SNF (grant nos. 310030_173085 and CRSII3_160780) and BMBF (grant RAPID; 01KI1723A). I.N.B. and M.B.M. were supported by the National Science Foundation Graduate Research Fellowship under grant nos. 2016217834 and 2019274212, respectively.

\section{Author contributions}

S. Pfaender, K.B.M., E.M., C.M.R., J.W.S. and V.T. designed the project. S. Pfaender, K.B.M., E.M., A.K., I.N.B., P.V., W.F., D.H., N.E., H.S., H.K.-W., M.H., H.-H.H., M.S., M.B.M. and G.Z. performed and analysed the in vitro experiments. K.B.M. performed and analysed the in vivo experiments with assistance from W.F. and N.W.H. M.W.-C. performed the histological analysis. D.T. performed the statistical analysis and analysis of the MHV RNA-seq dataset. J.N.K. performed the statistical analysis and analysis of the hAEC RNA-seq dataset. R.D., S. Pöhlmann, E.S. nd T.G. contributed to the design and implementation of the research. S. Pfaender, K.B.M. and J.W.S. wrote the manuscript. All authors contributed to editing the manuscript.

\section{Competing interests}

The authors declare no competing interests.

\section{Additional information}

Extended data is available for this paper at https://doi.org/10.1038/s41564-020-0769-y.

Supplementary information is available for this paper at https://doi.org/10.1038/ s41564-020-0769-y.

Correspondence and requests for materials should be addressed to C.M.R., J.W.S. or V.T. Reprints and permissions information is available at www.nature.com/reprints.

Publisher's note Springer Nature remains neutral with regard to jurisdictional claims in published maps and institutional affiliations.

(C) The Author(s), under exclusive licence to Springer Nature Limited 2020 

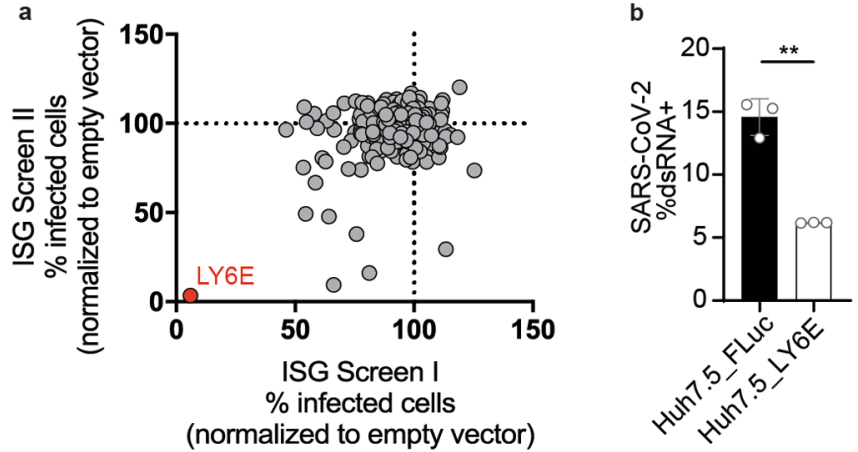

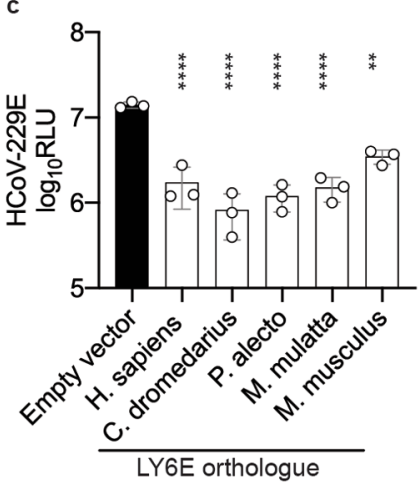

g

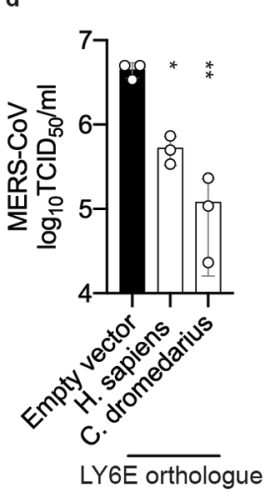

ACE2
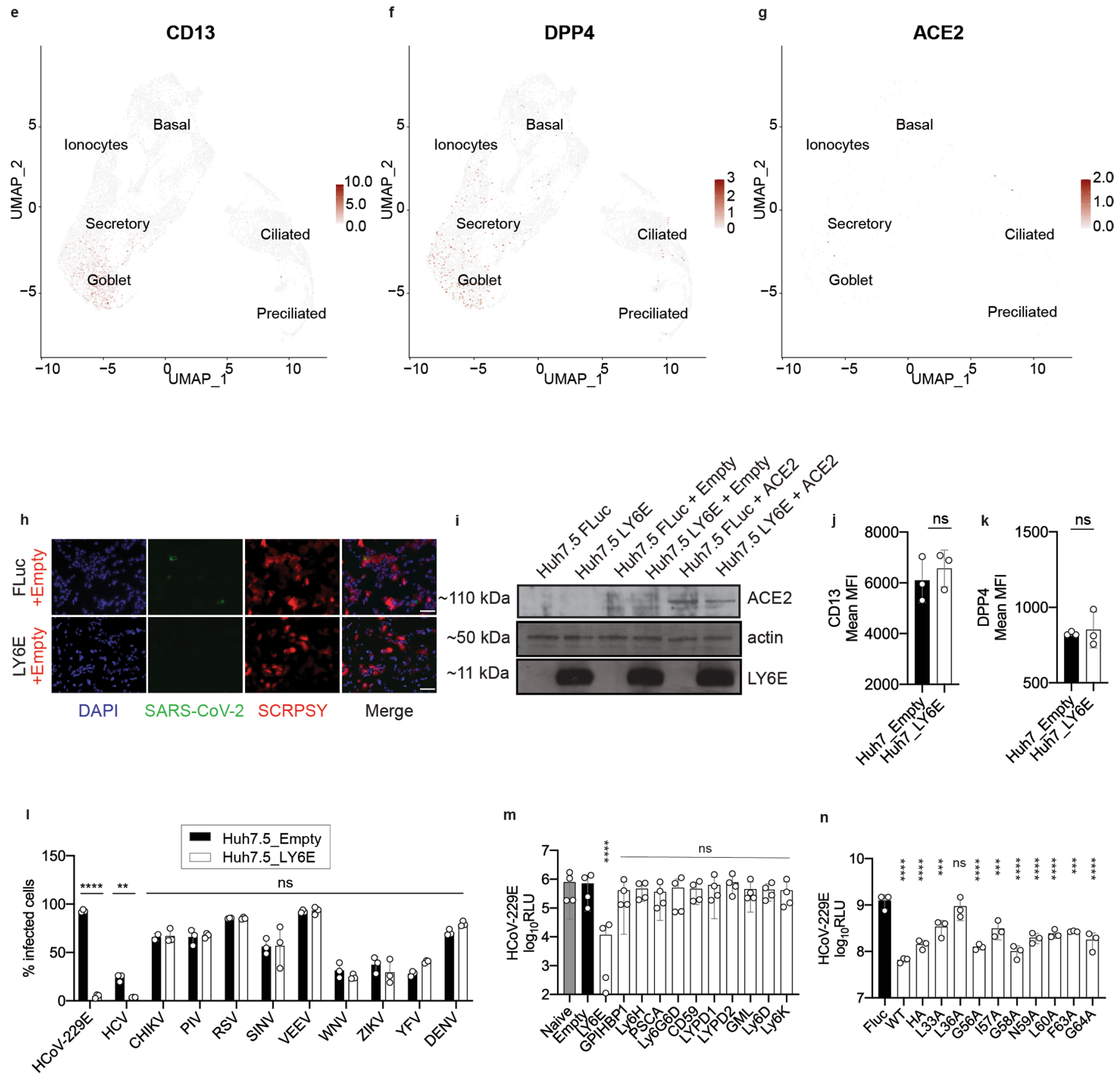

Extended Data Fig. 1 | See next page for caption. 
Extended Data Fig. 1 | The antiviral activity of LY6E is conserved, independent of CoV receptors, and extends to HCV. a, Duplicate screens depicting HCoV-229E infection (48 hours post-infection) in Huh7 cells expressing ISGs. b, SARS-CoV-2 infection of Huh7.5 cells expressing LY6E or a control (FLuc). c, HCoV-229E infection of Huh7.5 cells expressing vector control or human (H. sapiens), camel (C. dromedarius), bat (P. alecto), mouse (M. musculus), or rhesus (M. mulatta) LY6E orthologues. d, Stable LY6E or empty vector expressing Huh7.5 cells infected with MERS-CoV. e-g, UMAP visualization of CD13 (e) DPP4 (f), and ACE2 (g) expression and distribution among distinct cell types in hAEC cultures from 2 donors by scRNA-seq. h, SARS-CoV-2 infection of LY6E or control vector (FLuc) Huh7.5 cells co-expressing control vector (empty). Blue: DAPI, green: SARS-CoV-2 dsRNA, red: TagRFP encoded in SCRPSY-ACE2 vector. $\mathbf{i}$, Western blot of Huh7.5 expressing LY6E or FLuc and empty vector or ACE2. j, $\mathbf{k}$, Stable LY6E or empty vector expressing Huh7 cells were assessed for cell surface expression of CD13 (j) and DPP4 (k). I, Stable Huh7.5 cells expressing either LY6E or empty vector infected with HCoV-229E, HCV, CHIKV, hPIV-3, RSV, SINV, VEEV, WNV, ZIKV, YFV, and DENV. m, HCoV-229E-Rluc infection of naïve or stably transduced Huh7 cells expressing empty vector control or LY6/UPAR family members. $\mathbf{n}$, HCoV-229E-Rluc infection of Huh7 cells expressing control vector (FLuc), LY6E WT, LY6E HA or specific block mutants 9 . In $\mathbf{h}$, scale bars are $100 \mu \mathrm{M}$. Immunofluorescence and western blot images are depicted exemplarily from $n=3$ (h) and $n=3$ (i). Data depicts mean of independent biological replicates, $n=3(\mathbf{b}-\mathbf{d}, \mathbf{j}-\mathbf{n})$. Statistical significance was determined by two-tailed unpaired student's t-test with Welch's correction ( $\mathbf{b}, \mathbf{j}, \mathbf{k})$, ordinary one-way ANOVA with Dunnett `s correction for multiple comparison (c, d, $\mathbf{m}, \mathbf{n})$, two-way ANOVA followed by Sidak's multiple comparisons test (I). Error bars: SD (b-d, j-n). $P$ values (left-to-right): $\mathbf{b},{ }^{\star \star} p=0.0098 ; \mathbf{c},{ }^{\star \star \star \star}{ }^{\star \star *} p=<0.0001,{ }^{\star \star} p=0.0030$; d, ${ }^{\star} \mathrm{p}=0.0118,{ }^{\star \star} \mathrm{p}=0.0013 ; \mathbf{I},{ }^{\star \star \star \star \star} \mathrm{p}=>0.0001,{ }^{\star \star} \mathrm{p}=0.0095 ; \mathbf{m},{ }^{\star \star \star \star} \mathrm{p}=<0.0001 ; \mathbf{n},{ }^{\star \star \star \star \star} \mathrm{p}=<0.0001,<0.0001,{ }^{\star \star \star} \mathrm{p}=0.0005,{ }^{\star \star \star \star \star} \mathrm{p}=<0.0001$, ${ }^{\star \star \star \star} \mathrm{p}=0.0003{ }^{\star \star \star \star \star} \mathrm{p}=<0.0001,<0.0001,<0.0001,{ }^{\star \star \star} \mathrm{p}=0.0001,{ }^{\star \star \star \star} \mathrm{p}=<0.0001$. 
a

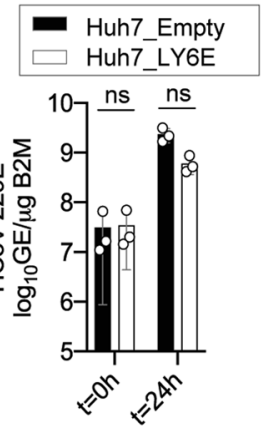

b

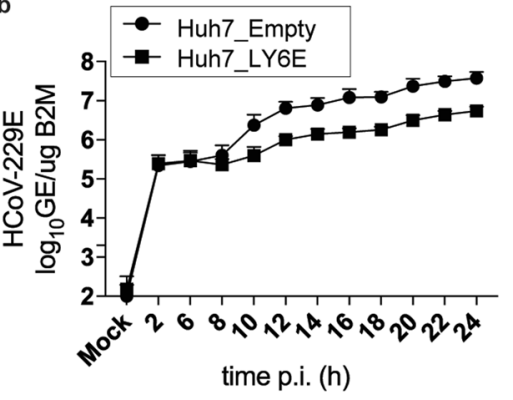

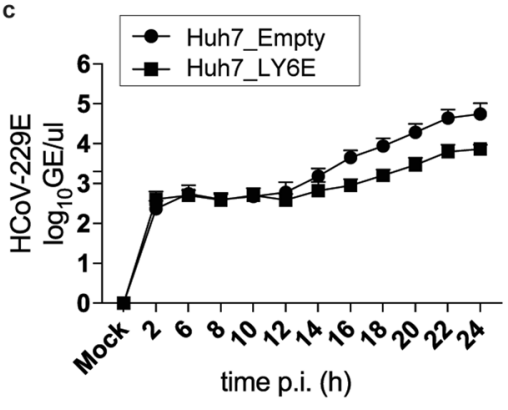

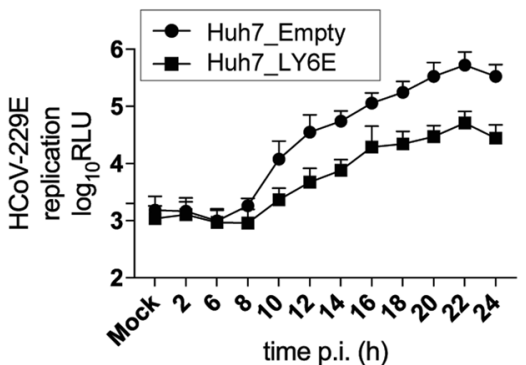

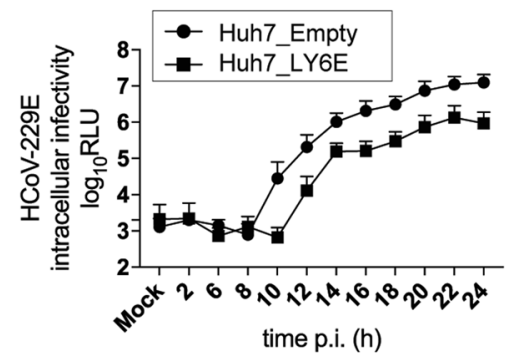

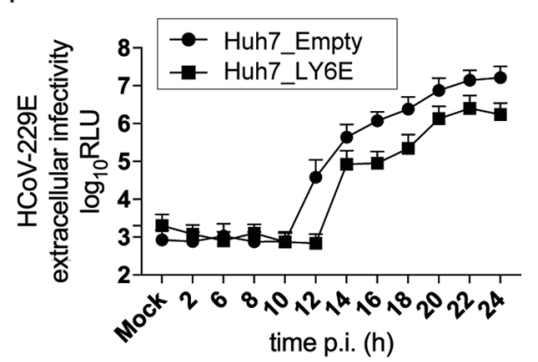

Extended Data Fig. 2 | LY6E does not affect CoV binding, replication, translation, assembly, or release. a, Stable LY6E expressing or empty control Huh7 cells were incubated with HCoV-229E and binding analyzed immediately ( $t=0 \mathrm{~h}$ ) or after incubation for 24 hours $(t=24 \mathrm{~h})$ by RT-qPCR. $\mathbf{b}-\mathbf{f}$, Stable LY6E expressing or control Huh7 cells were mock-infected or infected with HCoV-229E-Rluc. Cell lysates were harvested at the indicated time points and intracellular viral RNA was extracted, and viral replication detected via qRT-PCR (b). Cell supernatant was harvested, extracellular viral RNA was extracted, and viral replication detected via GRT-PCR (c). Cell lysates were harvested, and intracellular Renilla luciferase activity was detected upon cell lysis (d). Cells were subjected to 3 rounds of freeze/thaw cycles. Cell debris was removed, and the supernatant titrated on naïve Huh7 cells. Intracellular infectivity was determined (e). Supernatant was harvested and titrated on naïve Huh7 cells to determine extracellular infectivity (f). Data represent mean of independent biological replicates, $n=3(\mathbf{a}-\mathbf{f})$. Statistical significance was determined by two-way ANOVA followed by Sidak's multiple comparisons test (a). Error bars: SD (a-f). 
a
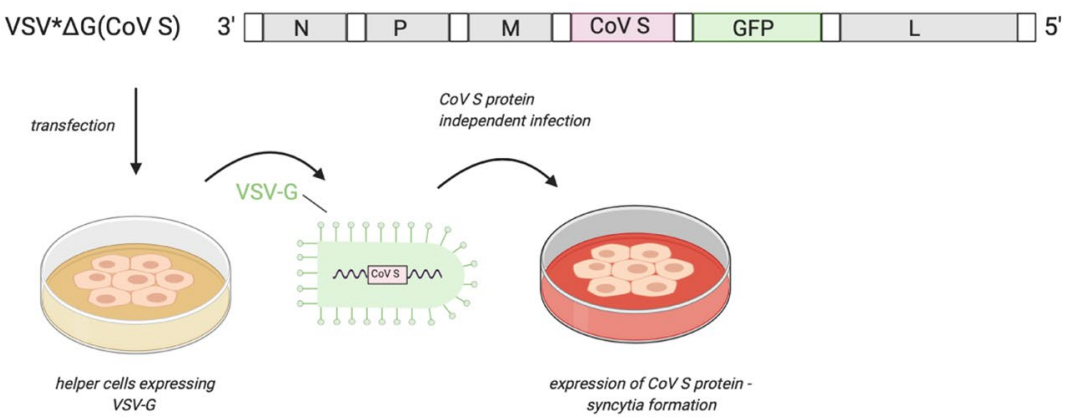

b

VSV* $\triangle \mathrm{G}$ (HCoV-229E S)

ডั

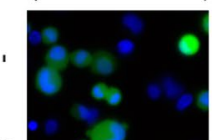

를
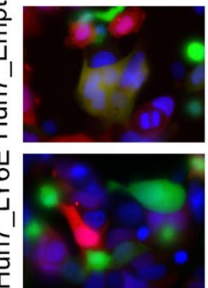

DAP

GFP

SCRPSY
$V S{ }^{*} \Delta G$
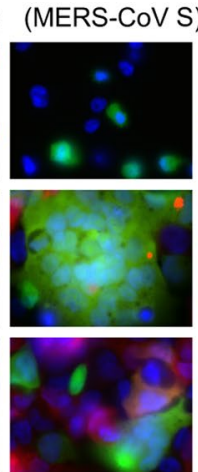
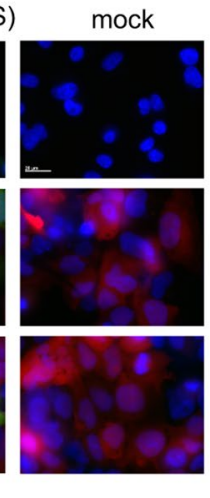

syncytia formation

\section{Extended Data Fig. 3 | Generation of recombinant VSV vector driving CoV S protein expression (VSV^ $\Delta G(C o V)$ ) and heterologous cell-cell fusion} assay. $\mathbf{a}$, Schematic depiction of the generation of recombinant $V S V^{\star} \Delta \mathrm{G}(\mathrm{CoV} \mathrm{S})$ expressing both CoV $\mathrm{S}$ protein and GFP reporter protein. The respective CoV S genes were inserted into the genomic VSV ${ }^{\star} \Delta G$ cDNA and recombinant virus was generated in BHK-G 43 cells expressing the VSV G protein. The recombinant virus produced in this way harbored the VSV G protein in the envelope allowing CoV S protein-independent infection of cells. Infection of cells with VSV* $\Delta G(C o V S)$ led to the expression of CoV S protein and consequent syncytia formation. $\mathbf{b}$, Heterologous syncytia formation assay. BHK-21 cells were infected with VSV G protein trans-complemented VSV* $\Delta G(C o V S)$ viruses or were mock-infected, followed by co-culture with LY6E or empty control Huh7 cells. Syncytia formation was determined. Blue: DAPI, green: GFP, red: TagRFP encoded in SCRPSY vector. c, Quantification of VSV* $\Delta$ G(CoV S) induced syncytia depicted as percentage syncytia area. Three independent areas were analyzed per biological replicate (circle, square, triangle). Data represent mean of independent biological replicates, $n=3(\mathbf{c})$. In $\mathbf{b}$, scale bar is $20 \mu \mathrm{M}$. Statistical significance was determined by two-way ANOVA followed by Sidak's multiple comparisons test (c). Error bars: SD. $P$ values: c (left-to-right), ${ }^{\star \star \star \star} p=6.0 \times 10^{-9},{ }^{\star \star \star \star} p=1.1 \times 10^{-15}$. 
a
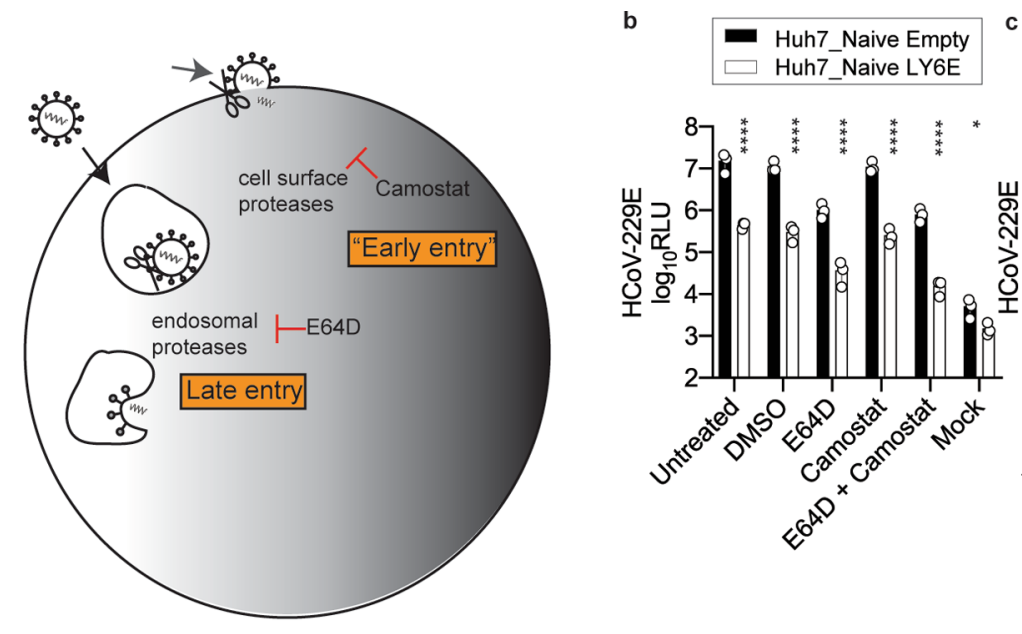

b

C

- Huh7_TMPRSS2 Empty Huh7_TMPRSS2 LY6E
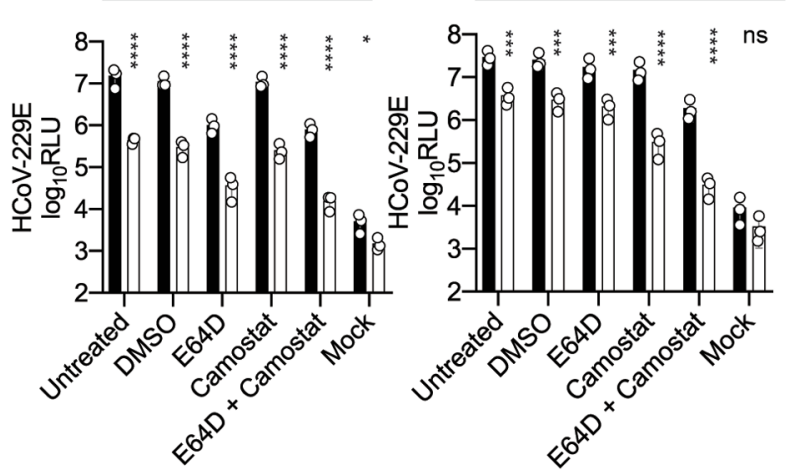

d

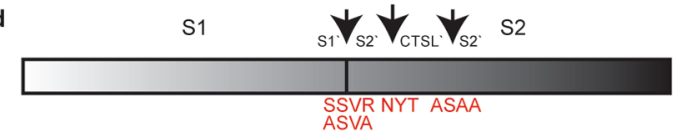

e

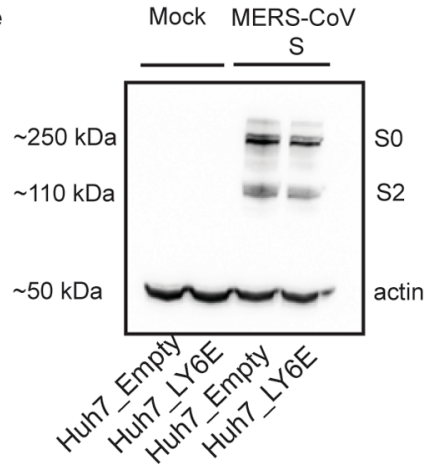

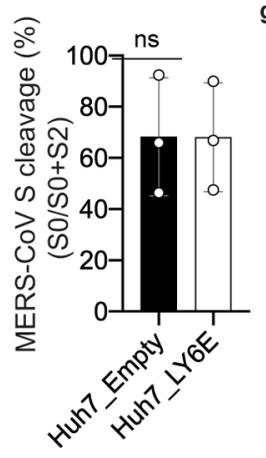

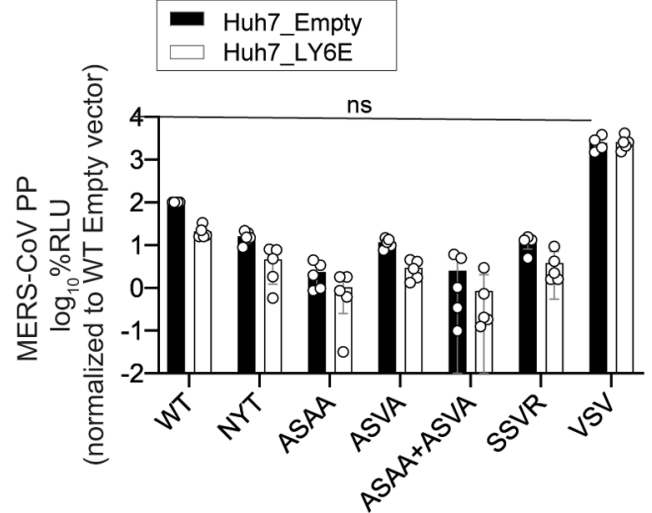

Extended Data Fig. 4 | The antiviral effect of LY6E is independent of proteolytic cleavage of CoV spike protein. a, Schematic depiction of cell entry routes of CoVs and intervention by selected compounds. b, c, LY6E or empty control-expressing Huh7 cells naïve for (b) or ectopically overexpressing TMPRSS2 (c) were pre-treated with the indicated compounds before infection with HCoV-229E-Rluc. d, Schematic depiction of the CoV spike (S) protein containing the subunits $\mathrm{S} 1$ and S2. Arrows indicate the S1/S2' cleavage site, a proposed cleavage site for cathepsin L (CTSL') and the S2' cleavage site. Amino acid exchanges disrupting the respective cleavage sites are depicted in red. e, Western blot of $\mathrm{S}$ cleavage in LY6E or empty control-expressing Huh7 cells transfected with a plasmid encoding for MERS-CoV S protein ( $\mathrm{SO}=$ uncleaved, $\mathrm{S} 2=\mathrm{S} 2$ subunit). f, MERS CoV S cleavage was analyzed by quantification of SO and S2 bands. g, LY6E or empty control-expressing Huh7 cells inoculated with CoV-pseudoparticles (pp) harboring MERS-CoV S WT or MERS-CoV S proteins containing various cleavage site mutations. Data represent mean of independent biological replicates, $n=3(\mathbf{b}), n=3$ (c), $n=3$ (e), $\mathrm{n}=3(\mathbf{f}), \mathrm{n}=5(\mathbf{g})$. Statistical significance was determined by two-way ANOVA followed by Sidak's multiple comparisons $(\mathbf{b}, \mathbf{c}, \mathbf{g})$ or two-tailed unpaired student's t-test with Welch's correction (f). Error bars: SD. $P$ values (left-to-right): $\mathbf{b},{ }^{\star \star \star \star \star} p=4.4 \times 10^{-9}, p=1.6 \times 10^{-9}, p=6.2 \times 10^{-9}, p=7.5 \times 10^{-10}, p=3.0 \times 10^{-10}$, ${ }^{\star} \mathrm{p}=0.0179 ; \mathbf{c}^{\star \star \star \star} \mathrm{p}=0.0007, \mathrm{p}=0.0005, \mathrm{p}=0.0006,{ }^{\star \star \star \star} \mathrm{p}=4.8 \times 10^{-8}, \mathrm{p}=1.8 \times 10^{-8}$. 


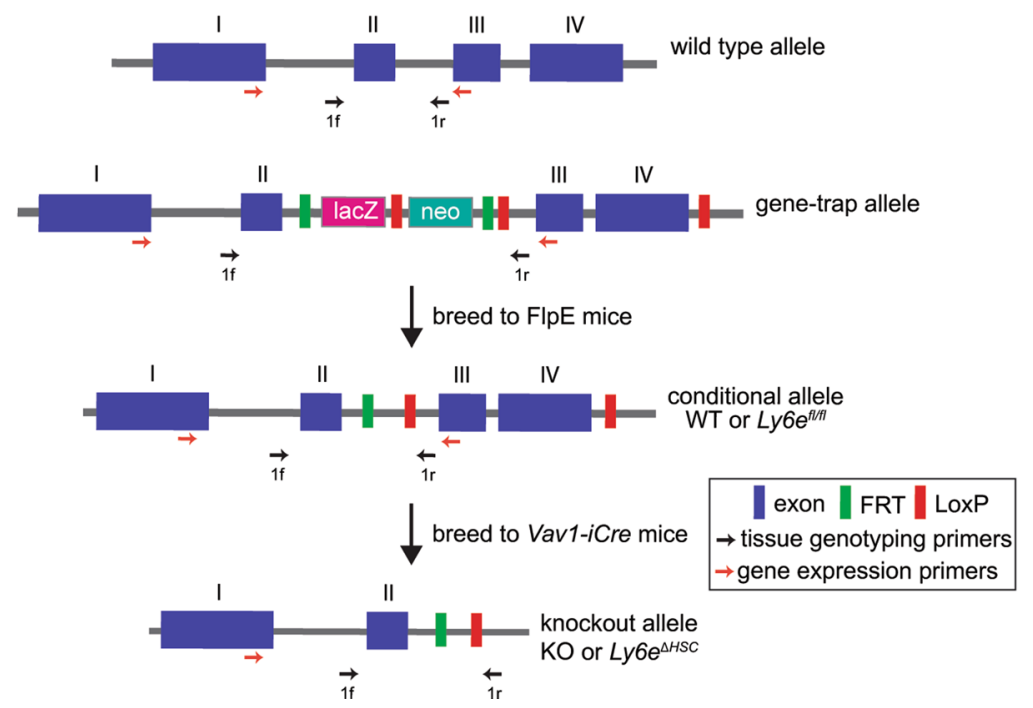

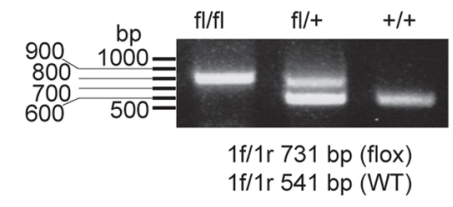

Bone marrow-derived macrophages

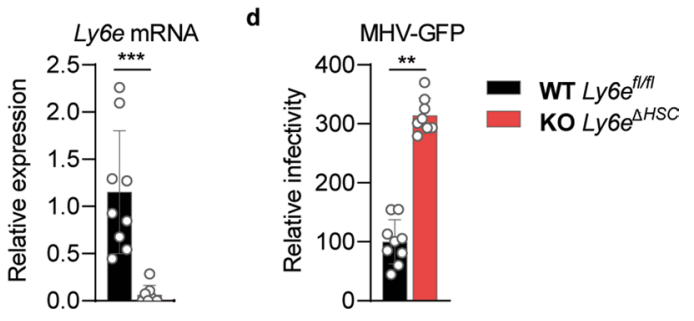

Extended Data Fig. 5 | Generation of hematopoietic Ly6e conditional knockout mouse. a, Strategy used to generate Ly6e ${ }^{\Delta H S C}$ mice. Hematopoietic-tissue specific ablation of Ly6e was achieved by crossing Ly6 $\mathrm{e}^{\mathrm{f} / \mathrm{fl}}$ mice with transgenic Vav1-iCre mice to remove the LoxP-flanked exon III and IV, resulting in a 17 amino acid truncated variant of the 130 amino acid full-length protein. Primers used for tissue genotyping and gene expression are also depicted as arrows. b, Gel electrophoresis of tissue genotyping PCR, representing $L y 6 \mathrm{e}^{f / / f l}, L y 6 \mathrm{e}^{\mathrm{fl/+}}$, and $L y 6 \mathrm{e}^{+/+}$mice. $\mathbf{c}$, LyGe gene expression in bone marrow-derived macrophages (BMDM). d, Infection of BMDM. For $\mathbf{c}-\mathbf{d}, n=9$ ( $\left.L y 6 \mathrm{e}^{f / f f}\right)$ or $\mathrm{n}=8$ ( $L y 6 \mathrm{e}^{\mathrm{AHSC}}$ ) mice from three pooled experiments. The gel shown in $\mathbf{b}$ is representative of all genotyping performed to identify $L y 6 \mathrm{e}^{f / / f l}$ mice. Data for $\mathbf{c}, \mathbf{d}$ is shown normalized to Ly6 $\mathrm{f}^{f / / f l}$ values. Statistical significance was determined by using two-tailed unpaired student's t-test with Welch's correction (c) or two-tailed ratio-paired t-test (d). Data are presented as mean values \pm SD (c-d). $P$ values: $\mathbf{c},{ }^{\star \star \star} p=0.0010 . \mathbf{d},{ }^{\star \star} p=0.0021$ 


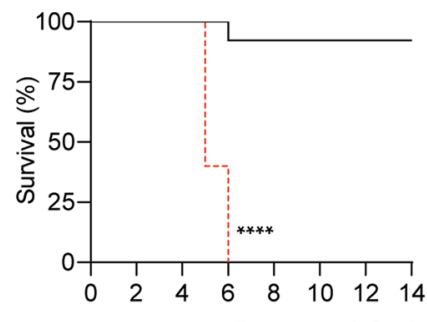

b

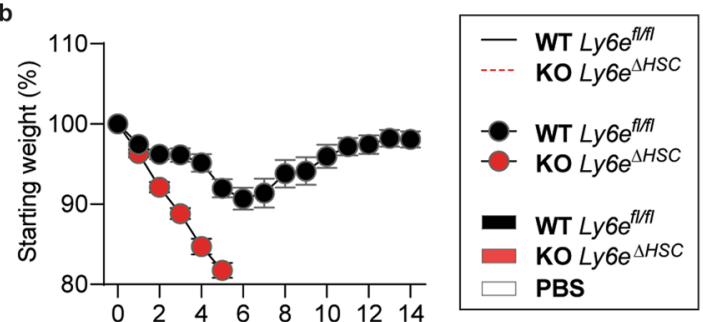

Days post-infection (50,000 PFU MHV-A59)
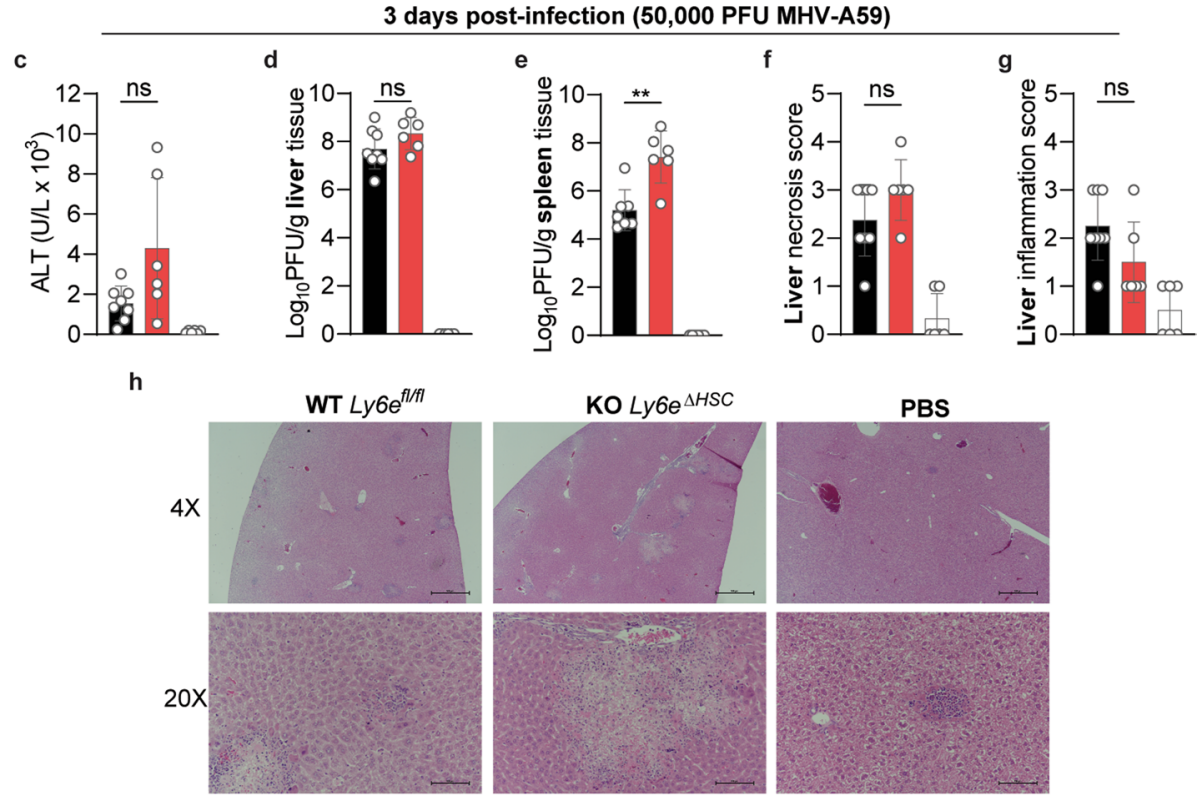

5 days post-infection (50,000 PFU MHV-A59)

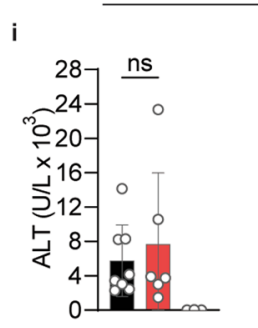

j
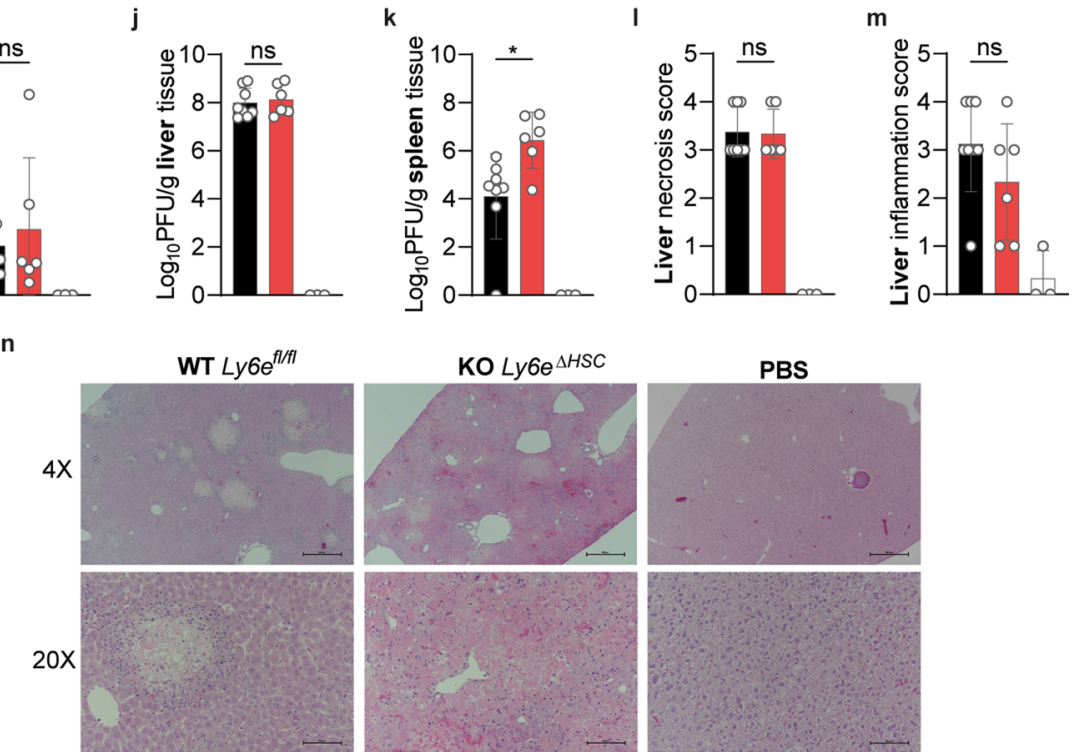

Extended Data Fig. 6 | Ly6 $\mathrm{e}^{\Delta H S C}$ mice are susceptible to mouse hepatitis virus. a, b, Male $L y 6 e^{f / f l}$ and $L y 6 e^{\Delta H S C}$ mice injected with PBS or MHV and monitored for survival (a) and weight loss (b). c-n, Mice were euthanized at 3- (c-h) or 5- (i-n) days post-infection for determination of serum ALT (c,i), viral titers in liver $(\mathbf{d}, \mathbf{j})$ and spleen $(\mathbf{e}, \mathbf{k})$, and liver necrosis and inflammation $(\mathbf{f}-\mathbf{h}, \mathbf{I}-\mathbf{n})$. For $\mathbf{a}, \mathbf{b}, \mathrm{n}=15$ for days $0-6, \mathrm{n}=14$ for days $6-14,\left(\right.$ Ly6 $\left.\mathrm{e}^{\mathrm{f} / \mathrm{fl})}\right), \mathrm{n}=10 \mathrm{for}$

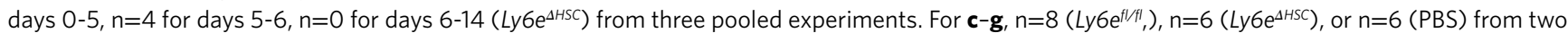
pooled experiments; images shown in $\mathbf{h}$ are representative of the same cohorts. For $\mathbf{i}-\mathbf{m}, \mathrm{n}=8\left(\operatorname{Ly} 6 \mathrm{e}^{f / / f l}, \mathrm{)}\right), \mathrm{n}=6\left(\mathrm{Ly} 6 \mathrm{e}^{\Delta H S C}\right)$, or $\mathrm{n}=3(\mathrm{PBS})$ from two pooled experiments; images shown in $\mathbf{n}$ are representative of the same cohorts. In $\mathbf{h}, \mathbf{n}$, scale bars are $500 \mu M(4 x)$ and $100 \mu M(20 x)$. Significance for was tested by two-sided Mantel-Cox test (a), two-tailed unpaired student's t-test with Welch's correction (c-e, i-k), two-tailed Mann-Whitney U test (f, $\mathbf{g}$, I, m). Data are presented as mean values \pm SEM (b) or SD $(\mathbf{c}-\mathbf{g}, \mathbf{i}-\mathbf{m}) . P$ value: $\mathbf{a},{ }^{\star \star \star \star}{ } \mathrm{p}=3.946 \times 10^{-6} ; \mathbf{e}^{\star \star \star}{ }^{*} \mathrm{p}=0.0026 ; \mathbf{k},{ }^{\star} \mathrm{p}=0.0119$. 
5 days post-infection (5 PFU MHV-A59)

Females
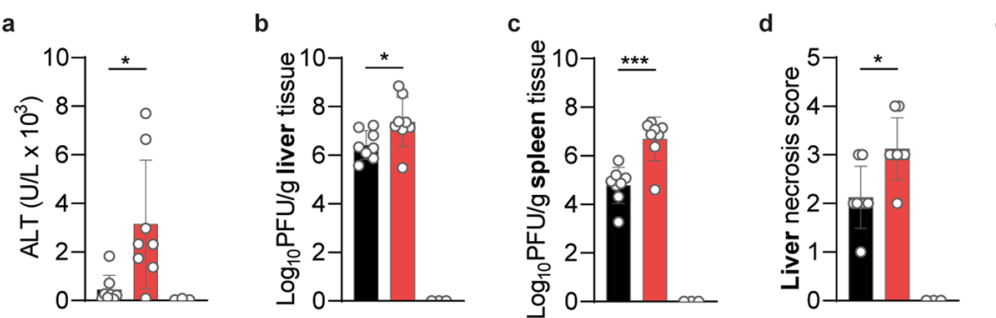

f

g

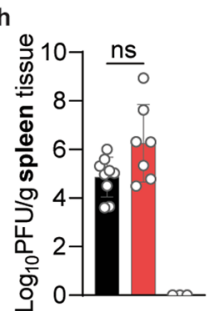

i
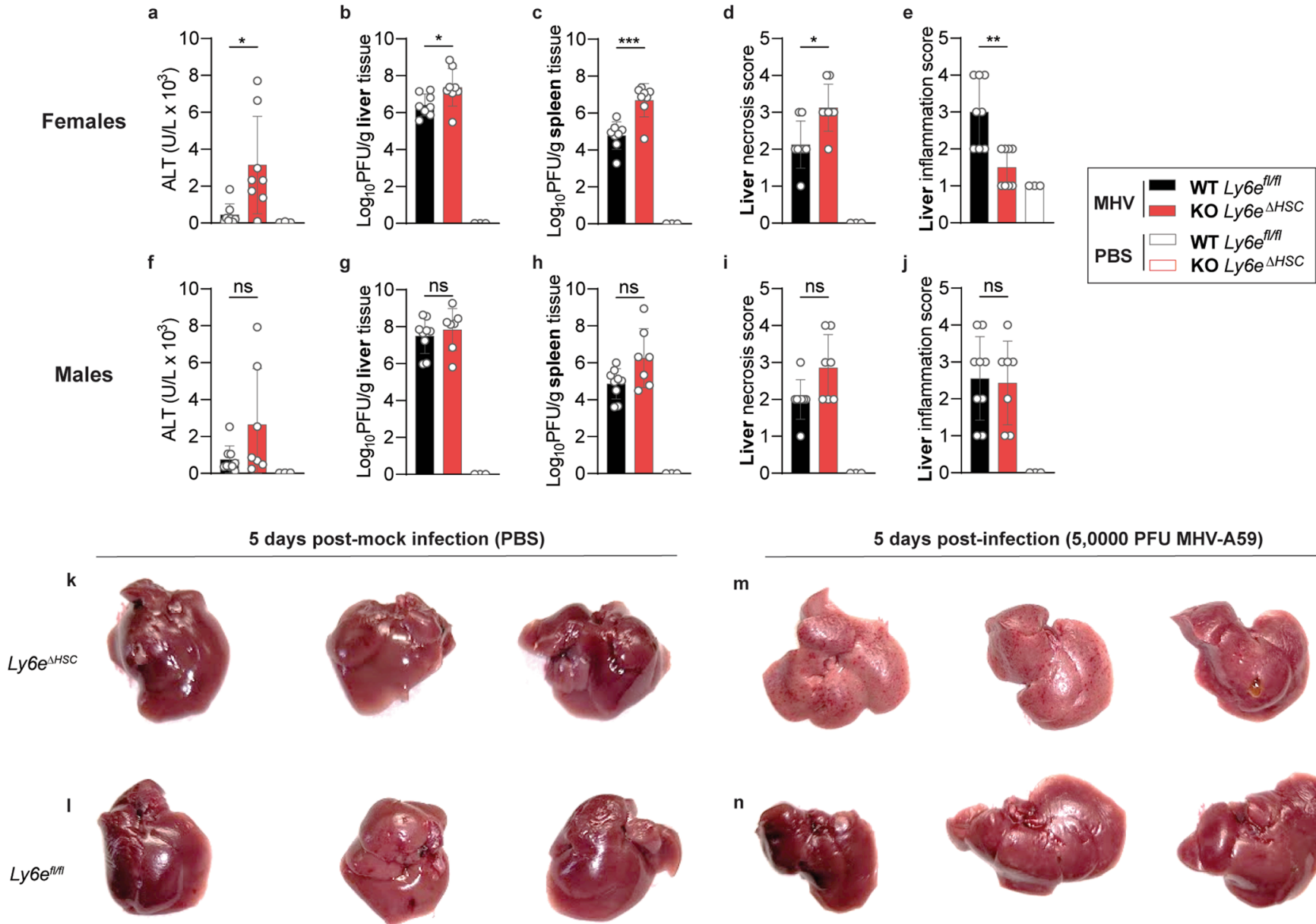

5 days post-mock infection (PBS)
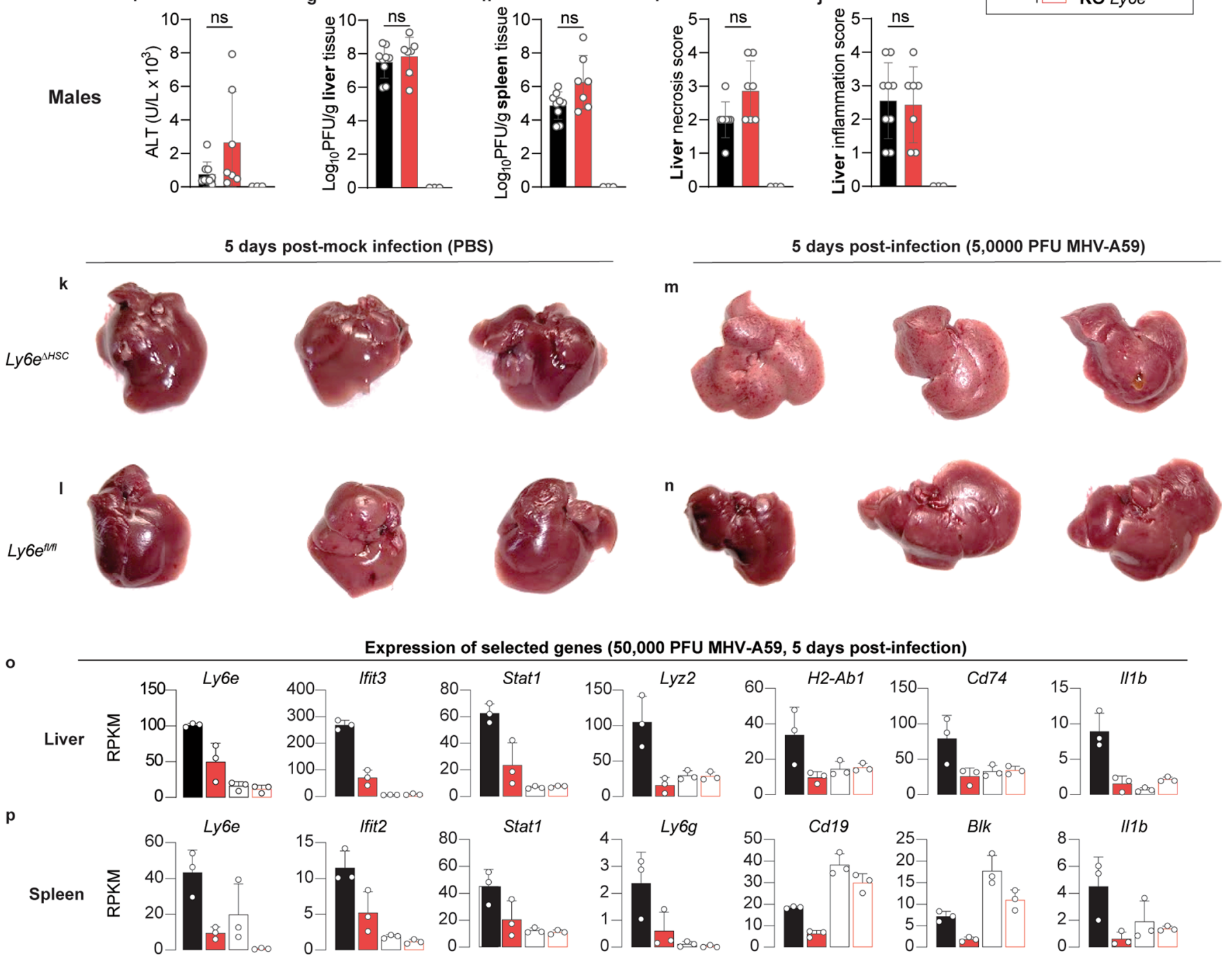

Extended Data Fig. $7 \mid$ Ly6 $\mathrm{e}^{\mathrm{sHSC}}$ mice have enhanced sensitivity to mouse hepatitis virus and a differential gene expression profile. a-j, Female (a-e) and male $(\mathbf{f}, \mathbf{g}) L y 6 e^{f / / f l}$ and $L y 6 e^{\Delta H S C}$ mice injected with PBS or MHV and assessed for serum ALT $(\mathbf{a}, \mathbf{f})$, viral titers in liver $(\mathbf{b}, \mathbf{g})$ and spleen $(\mathbf{c}, \mathbf{h})$, and liver necrosis and inflammation ( $\mathbf{d}, \mathbf{e}, \mathbf{i}, \mathbf{j}) . \mathbf{k}-\mathbf{n}$, Female $L y 6 e^{f / / f l}$ and $L y 6 e^{\Delta H S C}$ mice injected with PBS or MHV and whole livers were imaged. Mock-infected

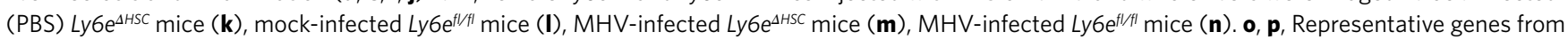
transcriptomic analysis of liver (o) and spleen (p) from MHV-infected and PBS-injected female $L y 6 e^{f / / f l}$ and $L y 6 e^{\Delta H S C}$ mice. For $\mathbf{a}-\mathbf{e}, n=8\left(L y 6 e^{f / / f l}\right), n=8$ $\left(L y 6 e^{\Delta H S C}\right)$, or $n=3$ (PBS) from two pooled experiments per sex. For $\mathbf{f}-\mathbf{j}, n=9\left(L_{y} 6 e^{f / f f l},\right), n=7\left(L y 6 e^{\Delta H S C}\right)$, or $n=3$ (PBS) two pooled experiments. For $\mathbf{k}-\mathbf{p}, n=3$. Statistical significance was determined by two-tailed unpaired student's t-test with Welch's correction (a-c, $\mathbf{f}-\mathbf{h})$, two-tailed Mann-Whitney U test (d, e, i, j). Data are presented as mean values $\pm \mathrm{SD}(\mathbf{a}-\mathbf{j} ; \mathbf{o}, \mathbf{p})$. $P$ value: $\mathbf{a},{ }^{\star} p=0.0234 ; \mathbf{b},{ }^{\star} p=0.0428 ; \mathbf{c},{ }^{\star \star \star} p=0.0004 ; \mathbf{d},{ }^{\star} p=0.0210 ; \mathbf{e},{ }^{\star \star} p=0.0054$. 


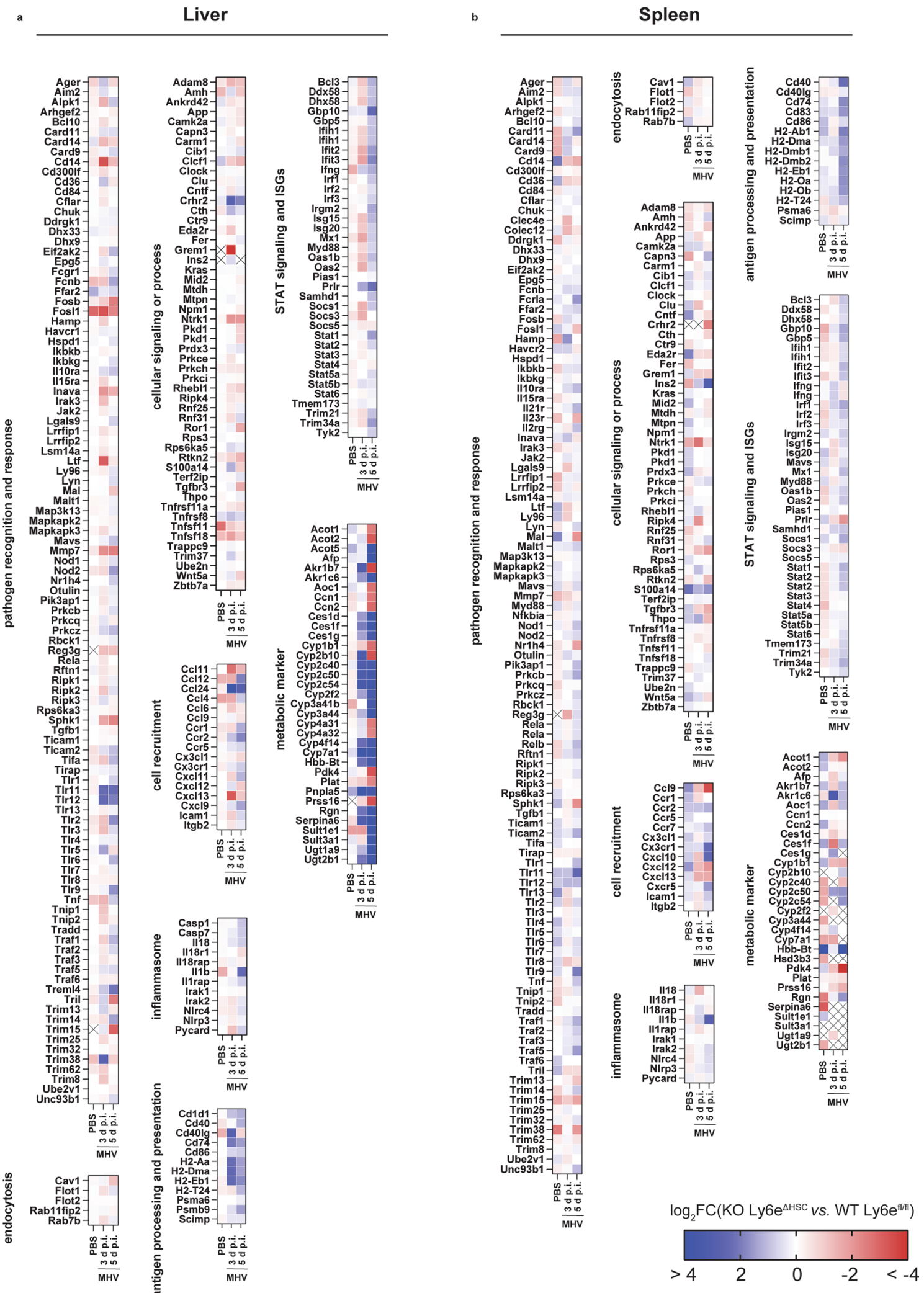

Extended Data Fig. 8 | Dynamic transcriptional changes in liver and spleen of $L y 6 \mathrm{e}^{\mathrm{HHSC}}$ vs $L y 6 \mathrm{e}^{\mathrm{f} / \mathrm{fl}}$ mice. Depicted are fold changes in liver and spleen gene expression from Ly6e $e^{\Delta H S C}$ mice compared to Ly $6 e^{f / f f l}$ mice. RPKM values from RNA-seq data for liver (a) and spleen (b) were used to calculate fold changes. Crossed out genes were not detected in either KO or WT mice at respective conditions. 



Forward scatter-LinA
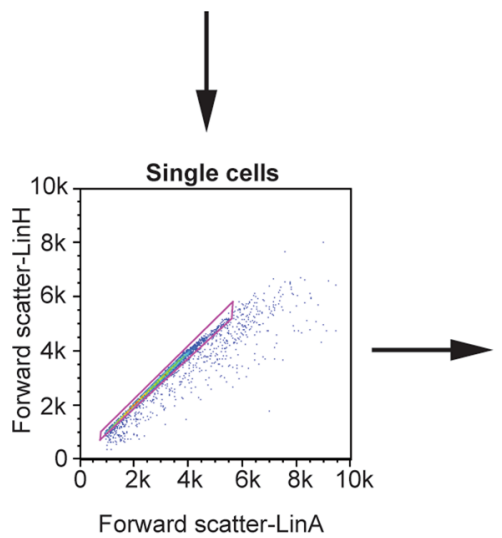
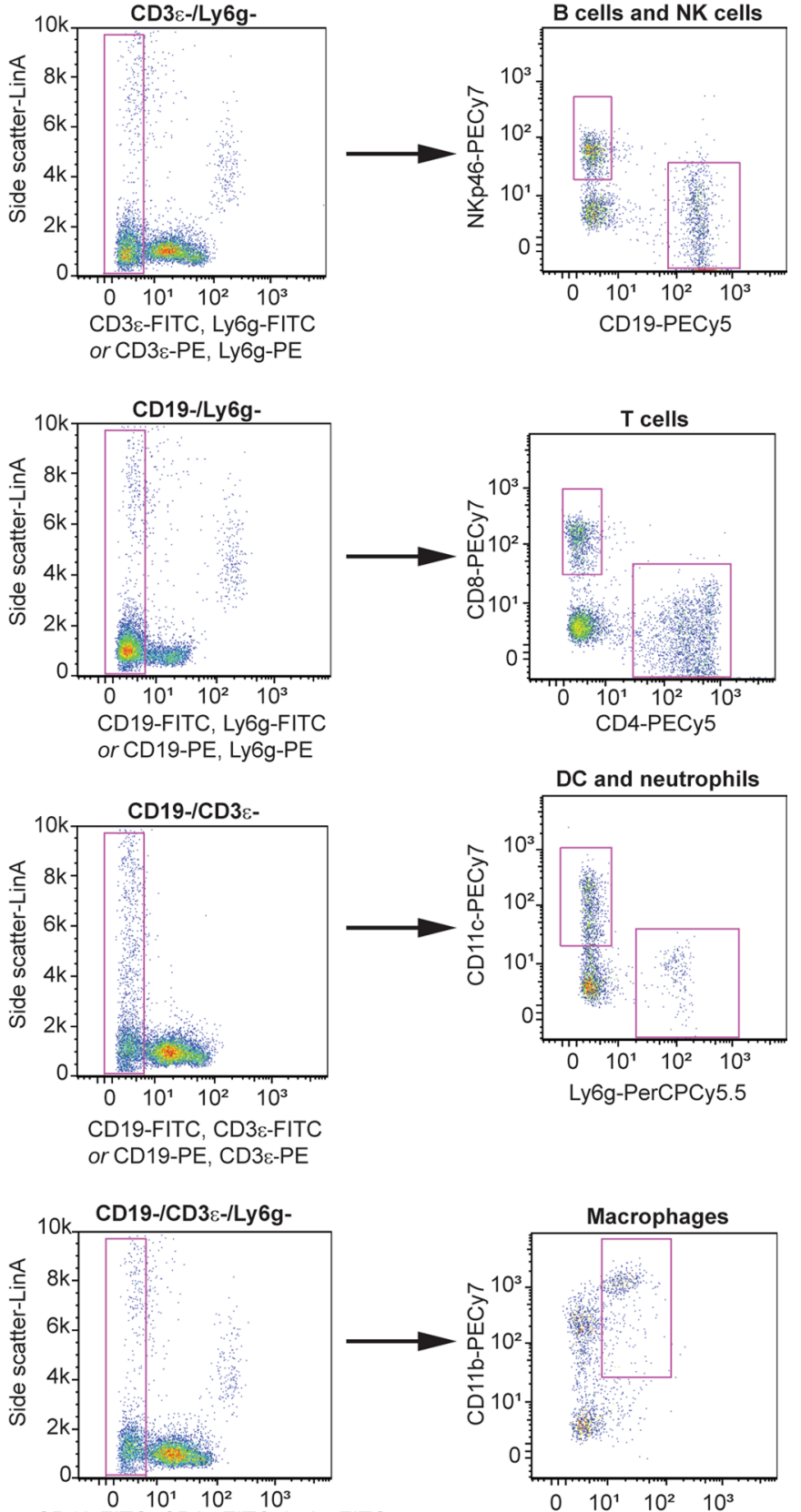

CD19-FITC, CD3e-FITC, Ly6g-FITC or CD19-PE, CD3e-PE, Ly6g-PE

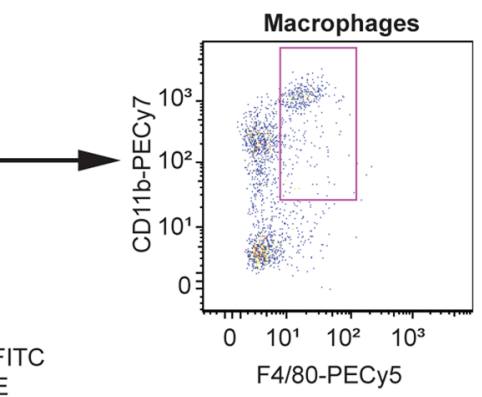

Extended Data Fig. 9 | Gating strategy for intrahepatic and splenic immune cell identification. Antibody-stained suspensions of isolated intrahepatic immune cells or splenic immune cells were first analyzed by forward scatter/side scatter to remove debris events, then gated for exclusion of a viability dye (Ghost Dye Violet 450), and finally for selection of single cell events. A dump-gate strategy was used to identify immune cell populations as indicated in the diagram. FITC-conjugated fluorophores were used for immunophenotyping experiments and PE-conjugated fluorophores were used for ex vivo infections. 


\begin{tabular}{|c|c|c|c|c|c|}
\hline & & WT $L y 6 e^{f / f f l}$ & & & WT $L y 6 \mathrm{e}^{f / f l}$ \\
\hline & & $\begin{array}{l}\text { KO Lybe } \\
\text { lfnar } \%\end{array}$ & BS & $\square$ & $\mathrm{KO} L y 6 \mathrm{e}^{\Delta H S C}$ \\
\hline
\end{tabular}

5 days post-infection (5,000 PFU MHV-A59)

Liver
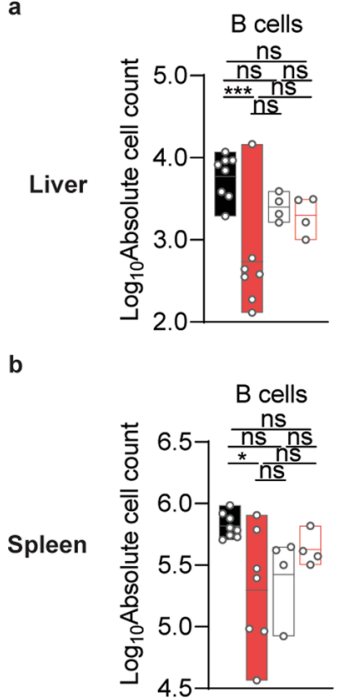
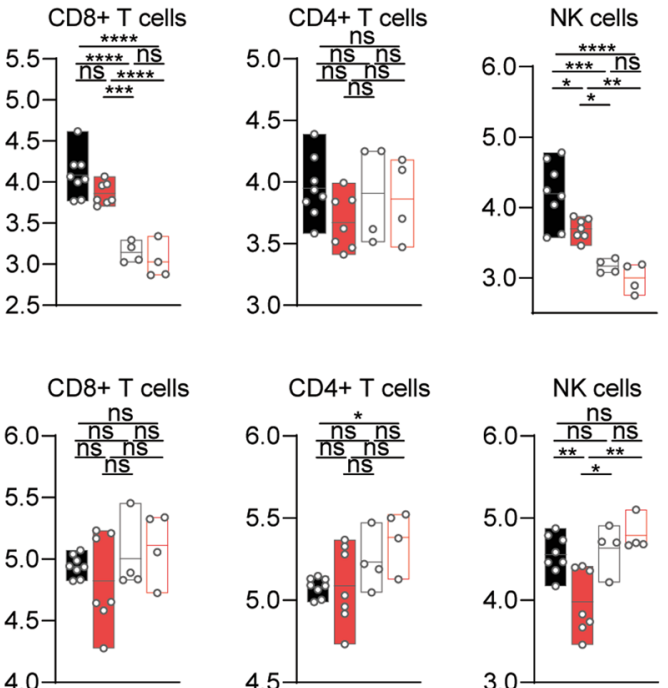
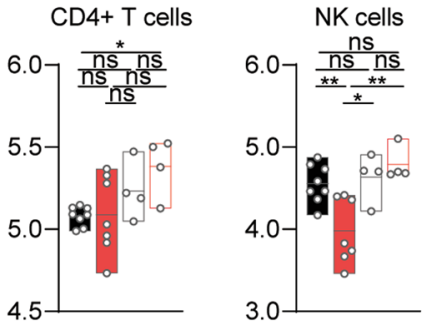

Dendritic cells
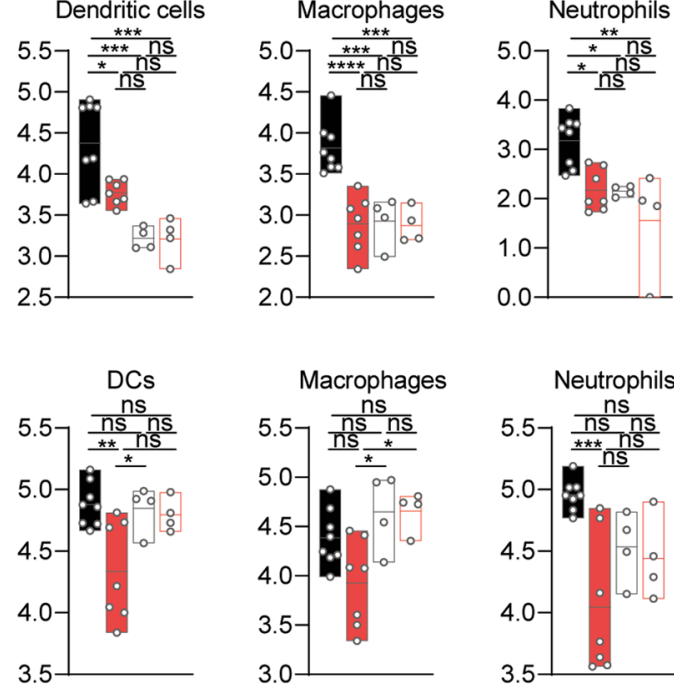
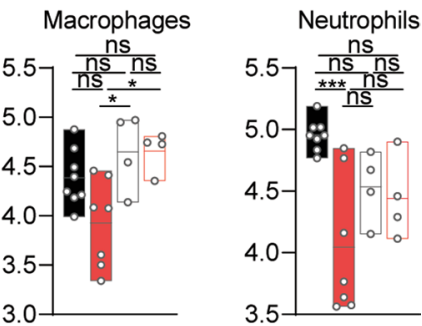

Ex vivo splenocytes infection (1 MOI PFU MHV-A59-GFP)

C
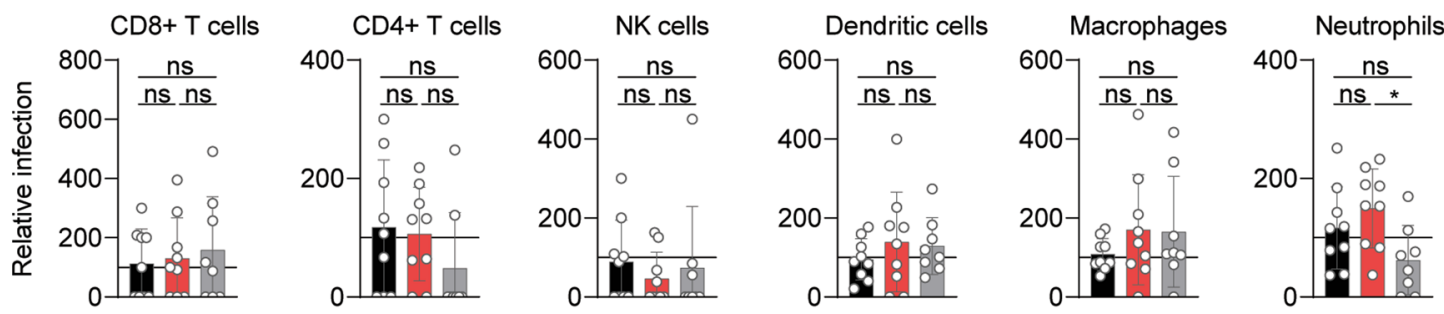

d

CD8+ T cells

CD4+ T cells
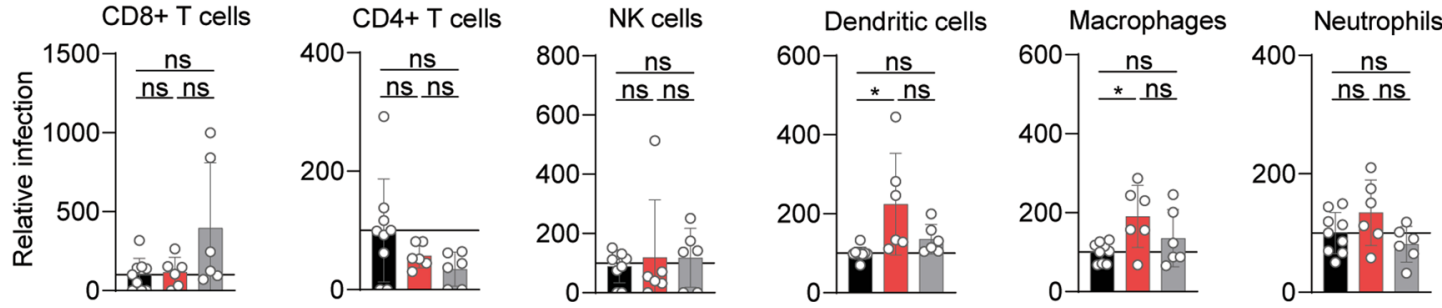

Extended Data Fig. 10 | Ly6e protects immune cells from mouse hepatitis virus infection. a, b, Immune cell counts from liver (a) and spleen (b) of MHV-infected or PBS-injected male mice. c, $\mathbf{d}$, Infection of cultured splenocytes from females (c) and males (d) normalized to average (line at 100) of

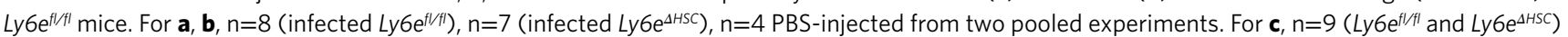
and $n=8$ (Ifnar-/-) from four pooled experiments. For $\mathbf{d}, n=9\left(L y 6 e^{f / / f / I}\right), n=6\left(L y 6 e^{\Delta H S C}\right)$, or $n=6($ Ifnar $/-)$ mice from four pooled experiments. Statistical significance was determined by one-way ANOVA with Tukey's multiple comparisons test (a-d). For box plots, center line indicates mean and upper and lower bounds respectively indicate maximum and minimum replicate values $(\mathbf{a}, \mathbf{b})$. Data are presented as mean values \pm SD (a-d). $P$ values (top-bottom,

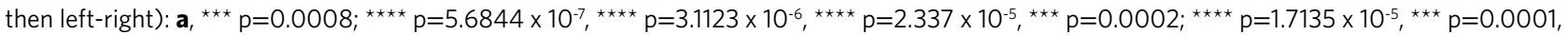
${ }^{\star} p=0.0216$, ${ }^{\star \star} p=0.0075,{ }^{\star} p=0.0494 ;{ }^{* \star \star} p=0.0002,{ }^{\star \star \star} p=0.0002, n s p=0.9999,{ }^{*} p=0.0182 ;{ }^{* \star \star} p=0.0004,{ }^{* \star \star} p=0.0008$, ${ }^{\star \star \star \star} p=7.354 \times 10^{-5}$;

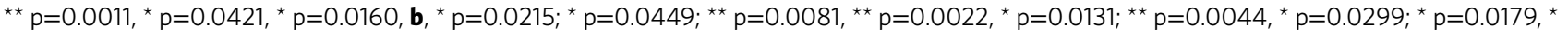
$\mathrm{p}=0.0194 ;{ }^{* \star *} \mathrm{p}=0.0007 . \mathbf{c},{ }^{\star} \mathrm{p}=0.0288 ; \mathbf{d},{ }^{\star} \mathrm{p}=0.0104 ;{ }^{*} \mathrm{p}=0.0240$. 


\section{Reporting Summary}

Nature Research wishes to improve the reproducibility of the work that we publish. This form provides structure for consistency and transparency in reporting. For further information on Nature Research policies, see Authors \& Referees and the Editorial Policy Checklist.

\section{Statistics}

For all statistical analyses, confirm that the following items are present in the figure legend, table legend, main text, or Methods section.

n/a $\mid$ Confirmed

$\square$ \. $\square$ The exact sample size $(n)$ for each experimental group/condition, given as a discrete number and unit of measurement

$\square$ \A statement on whether measurements were taken from distinct samples or whether the same sample was measured repeatedly

The statistical test(s) used AND whether they are one- or two-sided

$\square$ Only common tests should be described solely by name; describe more complex techniques in the Methods section.

Х $\square$ A description of all covariates tested

$\square$ \ A description of any assumptions or corrections, such as tests of normality and adjustment for multiple comparisons

A full description of the statistical parameters including central tendency (e.g. means) or other basic estimates (e.g. regression coefficient)

$\square$ AND variation (e.g. standard deviation) or associated estimates of uncertainty (e.g. confidence intervals)

$\triangle \square$ For null hypothesis testing, the test statistic (e.g. $F, t, r$ ) with confidence intervals, effect sizes, degrees of freedom and $P$ value noted

$\triangle \square$ Give $P$ values as exact values whenever suitable.

Х $\square$ For Bayesian analysis, information on the choice of priors and Markov chain Monte Carlo settings

Х $\square$ For hierarchical and complex designs, identification of the appropriate level for tests and full reporting of outcomes

Х $\square$ Estimates of effect sizes (e.g. Cohen's $d$, Pearson's $r$ ), indicating how they were calculated

Our web collection on statistics for biologists contains articles on many of the points above.

\section{Software and code}

Policy information about availability of computer code

Data collection flow cytometry:CellCapture v5.0 (Stratedigm)

Data analysis sequence analysis: Geneious Prime ${ }^{\circledR}$ 2019.2.3, SeqMan Pro, ApE v2.0.49.10

statistical analyses: GraphPad Prism version 8.3.0 for Windows

mRNA-Seq analysis: CLC Genomics Workbench 12.0.3

figures: GraphPad Prism version 8.3.0 for Windows, Adobe Illustrator v22.0.1, and Biorender Premium (2020)

flow cytometry: FlowJo v9 (TreeStar), FlowJo v10 (Treestar)

immunofluorescence analysis: ImageJ 2.0.0-rc-69/1.52p; Java 1.8.0_172 [64-bit]; Windows 1010.0

For manuscripts utilizing custom algorithms or software that are central to the research but not yet described in published literature, software must be made available to editors/reviewers. We strongly encourage code deposition in a community repository (e.g. GitHub). See the Nature Research guidelines for submitting code \& software for further information.

\section{Data}

Policy information about availability of data

All manuscripts must include a data availability statement. This statement should provide the following information, where applicable:

- Accession codes, unique identifiers, or web links for publicly available datasets

- A list of figures that have associated raw data

- A description of any restrictions on data availability

The authors declare that the data supporting the findings of this study are available within the article and its Supplementary Information files or are available on request. The RNA-seq data discussed in this publication have been deposited in the Gene Expression Omnibus (GEO) database, https://www.ncbi.nlm.nih.gov/geo (GSE146074). Data used for scRNA-seq analysis of hAEC has been previously reported (Kelly et al. 2020 bioRxiv - full citation in main text). Data used for RNA-seq analysis of LYGE induction in hAEC after viral infection has been previously reported (V'kowski et al. 2020 bioRxiv - full citation in main text). Genbank (https:// www.ncbi.nlm.nih.gov/genbank/) accession numbers for viral gene sequences used to generate S protein pseudoparticles: (VSV-G, NC_001560; HCoV-229E S, 


\section{Field-specific reporting}

Please select the one below that is the best fit for your research. If you are not sure, read the appropriate sections before making your selection.

$\searrow$ Life sciences

$\square$ Behavioural \& social sciences

Ecological, evolutionary \& environmental sciences

For a reference copy of the document with all sections, see nature.com/documents/nr-reporting-summary-flat.pdf

\section{Life sciences study design}

All studies must disclose on these points even when the disclosure is negative.

Sample size No statistical methods were used to determine sample size. Sample size was determined to be adequate based on relevant publications (PMID: 19124753, 30190477) experimental consistency and effect, generally 3 independent biological replicates assayed with technical replicates.

Data exclusions Ly6efl/fl;Vav1-iCre (KO or Ly6e delta HSC) mice were excluded post-mortem if Ly6e gene expression of splenocytes by qPCR equaled that of Ly6efl/fI WT mice. In these mice, Vav1-iCre was silenced which is why we checked both tail genotype and spleen gene expression.

In extended data figure 1, one outlier was removed from the CHIKV infection, as the infection control did not work. No infection was observed in the control cells. Since infection was observed in other biological replicates, we assumed a technical error occurred in this replicate and thus removed it.

Replication Aside from the CHIKV infection, all attempts to reproduce experimental findings were successful. Multiple independent experiments, enumerated in figure legends, were carried out for each assay with similar results.

Randomization For in vivo experiments, sex and age-matched animals of a given genotype were randomized to experimental groups, regardless of litter. Randomization was otherwise not used as measures were determined to be quantitative and not subjective to bias.

Blinding Blinding was not performed for group allocation during data collection or analysis outside of liver sample histology as analysis was performed through objective measures that were not subject to bias.

\section{Reporting for specific materials, systems and methods}

We require information from authors about some types of materials, experimental systems and methods used in many studies. Here, indicate whether each material, system or method listed is relevant to your study. If you are not sure if a list item applies to your research, read the appropriate section before selecting a response.

\begin{tabular}{l|l} 
Materials \& experimental sys \\
\hline $\mathrm{n} / \mathrm{a}$ & Involved in the study \\
\hline & $\bigotimes$ Antibodies \\
$\square$ & $\square$ Eukaryotic cell lines \\
$\square$ & $\square$ Animals and other organisms \\
$\square$ Clinical data
\end{tabular}

\begin{tabular}{l|l}
\multicolumn{2}{l}{ Methods } \\
\hline n/a & Involved in the study \\
$\square$ & $\square$ ChIP-seq \\
$\square$ & $\bigotimes$ Flow cytometry \\
$\square$ & $\square$ MRI-based neuroimaging
\end{tabular}

\section{Antibodies}

Antibodies used -MABI1: I1-Hybridoma ATCC ${ }^{\circledR}$ CRL-2700
-anti-CD16/CD32 (2.4G2), Tonbo, Cat \# 70-0161-U500
-anti-human MERS-CoV spike 1.6c7 (developed and kindly provided by BJ Bosch, no cat \# available)
-anti-ACE2 (R\&D Systems, AF933)
-anti-LY6E rabbit monoclonal antibody GEN-93-8-1 (Genentech) no catalogue number available
-anti-LY6E mouse monoclonal antibody 4D8.6.7 (Genentech) no catalogue number available
-Peroxidase-AffiniPure Donkey Anti-Rabbit IgG (Jackson Immunoresearch, catalogue number 711-035-152)
-Peroxidase-AffiniPure Donkey Anti-Human IgG (Jackson Immunoresearch, catalogue number 709-035-098)
-Monoclonal Anti- $\beta$-Actin-Peroxidase clone AC-15 (Sigma-Aldrich, catalogue number A3854)
-anti-HCoV-229E N protein (Anticuerpo Monoclonal, 1E7, Ingenasa, catalogue number M.30.HCo.I1E7)
-anti-dsRNA, clone J2 (Scicons, catalogue number 10010500)
-donkey anti-mouse AlexaFluor488-conjugated antibody (Jackson Immuno Research, catalogue number 715-545-150)
-anti-HCoV-OC43 N protein (catalogue number MAB9013, Millipore) 
-Goat anti-mouse IgG Cross-adsorbed secondary antibody, AlexaFluor488 (catalogue number A-11001, RRID: AB 2534069,

Thermo Fisher Scientific)

-anti-human CD13 Antibody, APC conjugated (clone WM15, BioLegend, catalogue number 301705)

-anti-human DPP4, FITC conjugated (cloneBA5b, BioLegend, catalogue number 302704)

-anti-CD3-PE (145-2C11, Tonbo Biosciences, catalogue number 50-0031)

-anti-CD3-FITC (145-2C11, Tonbo Biosciences, catalogue number 35-0031)

-anti-CD11c-PECy7 (N418, Tonbo Biosciences, catalogue number 60-0114)

-anti-Ly6G-PE (1A8, Tonbo Biosciences, catalogue number 50-1276)

-anti-Ly6G-FITC (1A8, Tonbo Biosciences, catalogue number 35-1276)

-anti-Ly6g-PerCPCy5.5 (1A8, Tonbo Biosciences, catalogue number 65-1276)

-MABI1: I1-Hybridoma ATCC ${ }^{\circledR}$ CRL-2700 ${ }^{\text {TM }}$

Lefrancios L, Lyles DS. The interaction of antibody with the major surface glycoprotein of vesicular stomatitis virus. I. Analysis of neutralizing epitopes with monoclonal antibodies. Virology 121: 157-167, 1982. PubMed: 6180550

-anti-ACE2 (R\&D Systems, AF933)

Validated by manufacturer by western blot

-anti-LY6E rabbit monoclonal antibody GEN-93-8-1 (Genentech)

Validated by ectopic overexpression and knockout of human LY6E by western blot.

Mar, K. B., Rinkenberger, N. R., Boys, I. N., Eitson, J. L., McDougal, M. B., Richardson, R. B., \& Schoggins, J. W. (2018). LY6E mediates an evolutionarily conserved enhancement of virus infection by targeting a late entry step. Nature communications, 9(1), 3603. https://doi.org/10.1038/s41467-018-06000-y

-anti-LY6E mouse monoclonal antibody 4D8.6.7 (Genentech)

Validated in current manuscript by knockout of human LY6E by western blot

-anti-human MERS-CoV spike 1.6c7 (kindly provided by BJ Bosch)

Validated by ability to neutralize MERS-CoV infection and syncytia formation

Widjaja, I., Wang, C., van Haperen, R., Gutiérrez-Álvarez, J., van Dieren, B., Okba, N., Raj, V. S., Li, W., Fernandez-Delgado, R., Grosveld, F., van Kuppeveld, F., Haagmans, B. L., Enjuanes, L., Drabek, D., \& Bosch, B. J. (2019). Towards a solution to MERS: protective human monoclonal antibodies targeting different domains and functions of the MERS-coronavirus spike glycoprotein. Emerging microbes \& infections, 8(1), 516-530. https://doi.org/10.1080/22221751.2019.1597644

-Monoclonal Anti- $\beta$-Actin-Peroxidase clone AC-15 (Sigma-Aldrich, A3854)

Validated by Western blot on manufacturer's website

-Peroxidase-AffiniPure Donkey Anti-Human IgG (Jackson Immunoresearch, catalogue number 709-035-098)

Validated in 4 publications on CiteAb database

-donkey anti-mouse AlexaFluor488-conjugated antibody (Jackson Immuno Research, catalogue number 715-545-150)

Validated in 196 publication on CiteAb database

-goat anti-mouse AlexaFluor488-conjugated antibody (catalogue number A28175, Thermo Fisher scientific)

Validated by immunofluorescence by manufacturer and by 6 publications on manufacturer's website

-Goat anti-mouse IgG Cross-adsorbed secondary antibody, AlexaFluor488 (catalogue number A-11001, RRID: AB 2534069,

Thermo Fisher Scientific)

Validated by immunflourescence by manufacturer and by $600+$ publications on manufacturer's website

-anti-HCoV-229E N protein (Anticuerpo Monoclonal, 1E7, Ingenasa) b

Generation and validation of this antibody by Western blot and ELISA was previously published.

Sastre, P., Dijkman, R., Camuñas, A., Ruiz, T., Jebbink, M. F., van der Hoek, L., Vela, C., \& Rueda, P. (2011). Differentiation between human coronaviruses NL63 and 229E using a novel double-antibody sandwich enzyme-linked immunosorbent assay based on specific monoclonal antibodies. Clinical and vaccine immunology : CVI, 18(1), 113-118. https://doi.org/10.1128/ CVI.00355-10

-anti-HCoV-OC43 N protein (MAB9013, Millipore)

Validated by manufacturer for immunofluorescence.

-anti-flavivirus group antigen 4G2 (MAB10216; RRID: AB_827205, EMD Millipore)

Validated for immunofluorescence and flow cytometry.

Hanners, N. W., Eitson, J. L., Usui, N., Richardson, R. B., Wexler, E. M., Konopka, G., \& Schoggins, J. W. (2016). Western Zika Virus in Human Fetal Neural Progenitors Persists Long Term with Partial Cytopathic and Limited Immunogenic Effects. Cell reports, 15(11), 2315-2322. https://doi.org/10.1016/j.celrep.2016.05.075 
-anti-human CD13 Antibody, APC conjugated (clone WM15, BioLegend)

validated by manufacturer on human peripheral blood for flow cytometry

-anti-human DPP4, FITC conjugated (cloneBA5b, BioLegend, catalogue number 302704)

validated by manufacturer on human peripheral blood for flow cytometry

The following antibodies were validated by the manufacturer on mouse splenocytes by flow cytometry:

-anti-CD16/CD32 (2.4G2, Tonbo Biosciences)

-anti-CD3-PE (145-2C11, Tonbo Biosciences)

-anti-CD3-FITC (145-2C11, Tonbo Biosciences)

-anti-CD11C-PECy7 (N418, Tonbo Biosciences)

-anti-Ly6G-PE (1A8, Tonbo Biosciences)

-anti-Ly6G-FITC (1A8, Tonbo Biosciences)

-anti-Ly6g-PerCPCy5.5 (1A8, Tonbo Biosciences)

-anti-CD11b-PECy7 (M1/70, Tonbo Biosciences)

-anti-CD19-PE (6D5, BioLegend)

-anti-CD19-FITC (1D3, Tonbo Biosciences)

-anti-CD19-PECy5 (6D5, BioLegend)

-anti-F4/80-PECy5 (BM8, BioLegend)

-anti-Nkp46-PECy7 (29A1.4, BioLegend)

-anti-CD4-PECy5 (GK1.5, Tonbo Biosciences)

-anti-CD8-PECy7 (53-6.7, Tonbo Biosciences)

\section{Eukaryotic cell lines}

Policy information about cell lines

Cell line source(s)

L929 cells (Source : 85011425 (Sigma, ECACC, 2017); authenticated 04/2019 by Thiel lab)

$17 \mathrm{Cl}-1$ cells (gift from Stanley Sawicki; not available commercially, authenticated 04/2019 by Thiel lab)

Huh7 cells (gift from Volker Lohman, University of Heidelberg; not available commercially, authentication was done in Heidelberg)

VeroB4 and VeroE6 (obtained from Marcel Müller, Charité, Berlin; authentication done in Berlin)

Huh7.5 cells (Originate from C. Rice lab, authenticated by Schoggins lab in 2018)

A549 cells (ATCC cat CCL-185, authenticated by Schoggins lab in 2018)

BHK-21 (DSMZ collection \# ACC61)

BHK-G43 cells were generated as described before (PMID: 15831958) and kindly provided by Gert Zimmer. Cells originated

from a commercial source, DSMZ collection \# ACC61.

STAT1-/- fibroblasts (gift from J.-L. Casanova, authenticated by Schoggins lab in 2018)

293LTV were obtained from Cell Biolabs, Inc (cat\#LTV-100)

HCT-8 (ATCC cat CCL-244)

Authentication

Thiel lab cell lines: Profiling of cell line was done using highly-polymorphic short tandem repeat loci (STRs). Fragment analysis was done on an ABI3730xI (Life Technologies) and the resulting data were analyzed with GeneMarker software (Softgenetics).

Schoggins lab cell lines: Common human cells lines were authenticated with STR analysis using the ATCC Cell Line Authentication service.

The identity of Huh7 cells has been verified by a Mulitiplex human cell line authentication test via SNP profiling (Multiplexion, Immenstaad, Germany).

VeroB4 and VeroE6 were authenticated by CytB sequencing using published species-specific primers (primers from: Irwin DM, Kocher TD, Wilson AC (1991) Evolution of the cytochrome b gene of mammals. J Mol Evol 32: 128-144.)

BHK-21 and BHK-G43 were obtained from commercial sources and thus not secondarily authenticated.

Mycoplasma contamination

Thiel lab: all cell lines in our laboratory (including L929 cells, 17Cl-1 cells, Huh7 cells, VeroB4 and VeroE6, A549 cells, STAT1-/fibroblasts, BHK-21 and BHK-G43) are routinely screened for mycoplasma contamination and were tested negative.

Schoggins lab: All cell lines are routinely tested for mycoplasma using a PCR based assay and were tested negative (Vendor GeM Mycoplasma Detection Kit from Sigma Cat.\#MP0025-1KT).

Commonly misidentified lines (See ICLAC register)

none

\section{Animals and other organisms}

Policy information about studies involving animals; ARRIVE guidelines recommended for reporting animal research

Laboratory animals

Ly6etm1a ES cells were obtained from the EUCOMM consortium59consortium59 and microinjected into C57BL/6J blastocysts by the UTSW Transgenic Technology Center. Chimeric mice with germline transmission were bred to obtain Ly6etm1a/+ offspring. Ly6etm1a/+ mice were crossed with FLPe-expressing mice (B6N.129S4-Gt(ROSA)26Sortm1(FLP1)Dyn/J, \#16226, Jackson 
Laboratories) to obtain Ly6efl/+ offspring, which were bred to homozygosity. Conditional Ly6efl/fl mice were bred to Vav1-iCre transgenic mice (B6.Cg-Commd10Tg(Vav1-icre)A2Kio/J, \#008610, Jackson Laboratories) to obtain Ly6e $\Delta \mathrm{HSC} /+$ (Ly6efl/+; Vav1iCre) offspring. Ly6e $\Delta \mathrm{HSC} /+$ mice were bred to obtain Ly6e $\Delta \mathrm{HSC}$ (Ly6efl/fl; Vav1-iCre) offspring, which harbor a deletion of exon 3 and 4 in hematopoietic stem cells (HSC). Experimental animals were obtained by crossing Ly6e $\Delta \mathrm{HSC}$ and Ly6efl/fl mice. Littermates were used for the majority of experiments when possible; otherwise mice of similar age (within 2 weeks) were used. Sample size was chosen based on published studies and no randomization or blinding was performed aside from scoring of liver histology. Genotype was confirmed by PCR of genomic DNA in-house or outsourced to Transnetyx. Ablation of Ly6e was confirmed by qPCR in immune cells from spleen, liver, or bone marrow. Animal studies were carried out in specific-pathogenfree barrier facilities managed and maintained by the UTSW Animal Resource Center. Ifnar-/- mice on a C57BL/6J background were a kind gift from N. Yan. . Facilities are maintained at an acceptable range of $68-79^{\circ} \mathrm{F}$ at a humidity of $30-70 \%$ on a 12 hour dark/12 hour light cycle.

Wild animals

Study did not involve wild animals

Field-collected samples

study did not involve samples collected from the field

Ethics oversight

II procedures used in this study complied with federal and institutional guidelines enforced by the UTSW Institutional Animal Care and Use Committee (IACUC) and were granted institutional approval after veterinary and committee review.

Note that full information on the approval of the study protocol must also be provided in the manuscript.

\section{Flow Cytometry}

Plots

Confirm that:

\The axis labels state the marker and fluorochrome used (e.g. CD4-FITC).

\The axis scales are clearly visible. Include numbers along axes only for bottom left plot of group (a 'group' is an analysis of identical markers).

$\bigotimes$ All plots are contour plots with outliers or pseudocolor plots.

A numerical value for number of cells or percentage (with statistics) is provided.

\section{Methodology}

Sample preparation

Instrument

Software

Cell population abundance

\begin{abstract}
All primary cells were maintained in 10\% FBS/10 mM HEPES/1 mM sodium pyruvate/2 mM L-glutamine/1x p-s/RPMI (cRPMI2) unless otherwise indicated.

Primary bone marrow derived macrophages (BMDM) were prepared by isolating marrow from femur/tibia, lysing red blood cells, and culturing hematopoietic stem cells in M-CSF for 5 days. Viable cells were quantified using trypan blue exclusion. BMDM were plated at $2.5 \times 104$ cells per well in non-treated 24-well tissue culture plates. Cells were infected the next day with $0.1 \mathrm{MOI} \mathrm{MHV}$ A59-GFP and isolated 6 hours post-infection for analysis by flow cytometry.

Splenocytes were prepared by mashing whole spleens against a $70 \mu \mathrm{M}$ cell strainer. Red blood cells were removed by using RBC lysis buffer (Tonbo Biosciences). Viable cells were quantified using trypan blue exclusion. For in vitro infection, splenocytes were plated at $1 \times 106$ cells per well in non-treated 6 -well tissue culture plates. Cells were infected the next day with $1 \mathrm{MOI}$ MHV-A59GFP and isolated 6 hours post-infection. Infected cells were stained with a fluorescent viability dye (Ghostdye Violet 450, Tonbo Biosciences) and fixed in 1\% PFA/PBS. The next day, fixed cells were treated with anti-CD16/CD32 (Tonbo Biosciences) and then stained with antibodies that recognize surface lineage markers and analyzed by flow cytometry.

Livers were perfused by PBS injection into the inferior vena cava and out of the portal vein. Blanched livers were minced with sterile scissors and mashed against a $70 \mu \mathrm{M}$ cell strainer. Hepatocytes and large debris were pelleted at $60 \times \mathrm{g}$ for 1 minute, $22^{\circ}$ C, with no brake. Intrahepatic immune cell (IHIC) and residual hepatocyte containing supernatants were pelleted at $480 \times \mathrm{g}$ for 8 minutes, $22^{\circ} \mathrm{C}$, with max brake and resuspended in 37.5\% Percoll (Sigma-Aldrich)/cRPMI2. Remaining hepatocytes were separated from IHIC by centrifugation at 850 x g for 30 minutes, $22^{\circ} \mathrm{C}$, with no brake. Red blood cells were removed from the resulting pellet with $\mathrm{RBC}$ lysis buffer (Tonbo Biosciences). Viable cells were quantified using trypan blue exclusion. IHIC and splenocytes $(4 \times 105)$ from infected or mock-infected mice were stained with a fluorescent viability dye (Ghostdye Violet 450 , Tonbo Biosciences), treated with anti-CD16/CD32 (Tonbo Biosciences), stained with antibodies that recognize surface lineage markers, and then fixed in 1\% PFA/PBS. Fixed volumes of cell suspensions were analyzed by flow cytometry the next day. Absolute cell counts were determined by multiplying final number of lineage marker-positive cells by dilution factor used to normalize cell counts for antibody staining.
\end{abstract}

The flow gating strategy for liver and spleen immune cells is included in Extended Data Figure 9.

1000 Flow Cytometer with a A600 96-well plate high throughput extension

CellCapture software (Stratedigm)

MHV infection affected cell abundance. Range of cell numbers recovered includes PBS and MHV-injected mice. From liver:

CD4+ T cells - 150-1200

CD8+ T cells - 55-2000

macrophages - 39-879

dendritic cells - 50-1977

neutrophils - 0-190 
B cells - 29-465

NK cells - 42-1291

in spleen:

CD4+ T cells - 273-1350

CD8+ T cells $-190-1119$

macrophages - 87-533

dendritic cells - 87-774

neutrophils - 58-846

B cells- $1413-5300$

NK cells - 65-400

Gating strategy

Antibody-stained suspensions of isolated intrahepatic immune cells or splenic immune cells were first analyzed by forward scatter/side scatter to remove debris events, then gated for exclusion of a viability dye, and finally for selection of single cell events. A dump-gate strategy was used to identify immune cell populations as indicated in the diagram. Boundaries of gates were determined by use of single color control samples.

$\bigotimes$ Tick this box to confirm that a figure exemplifying the gating strategy is provided in the Supplementary Information. 